NATIONAL LABORATORY

MANAGED BY UT-BATTELLE

FOR THE DEPARTMENT OF ENERGY

Light Water Reactor Sustainability Program

\title{
Analysis of Phase Transformation Studies in Solute Addition Alloys
}

August 2014

Prepared by

L. Tan, K.G. Field and J.T. Busby

Oak Ridge National Laboratory

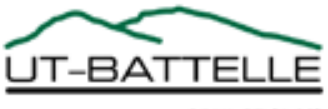


This report was prepared as an account of work sponsored by an agency of the United States Government. Neither the United States Government nor any agency thereof, nor any of their employees, makes any warranty, express or implied, or assumes any legal liability or responsibility for the accuracy, completeness, or usefulness of any information, apparatus, product, or process disclosed, or represents that its use would not infringe privately owned rights. Reference herein to any specific commercial product, process, or service by trade name, trademark, manufacturer, or otherwise, does not necessarily constitute or imply its endorsement, recommendation, or favoring by the United States Government or any agency thereof. The views and opinions of authors expressed herein do not necessarily state or reflect those of the United States Government or any agency thereof. 
Light Water Reactor Sustainability

\section{Analysis of Phase Transformation Studies in Solute Addition Alloys}

L. Tan, K.G. Field and J.T. Busby

Oak Ridge National Laboratory

Date Published: August 2014

Prepared under the direction of the

U.S. Department of Energy

Office of Nuclear Energy

Light Water Reactor Sustainability

Materials Aging and Degradation Pathway

Prepared by

OAK RIDGE NATIONAL LABORATORY

Oak Ridge, Tennessee 37831-6283

managed by

UT-BATTELLE, LLC

for the

U.S. DEPARTMENT OF ENERGY

under contract DE-AC05-00OR22725 
This page intentionally left blank 


\section{CONTENTS}

Page

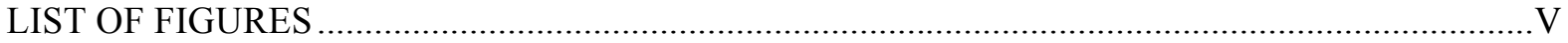

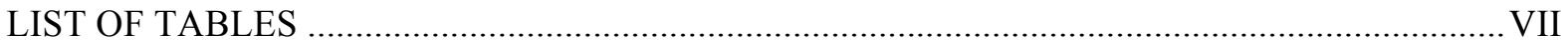

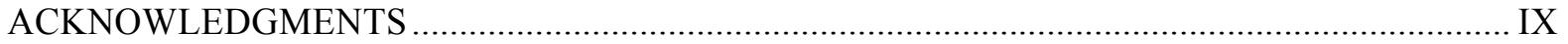

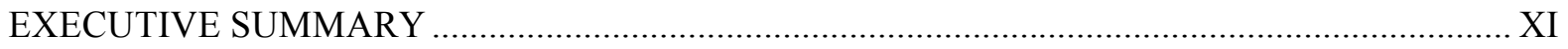

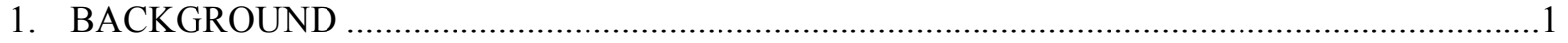

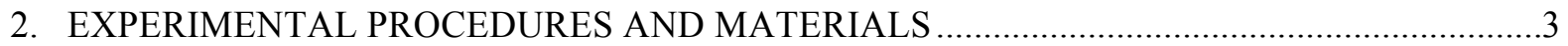

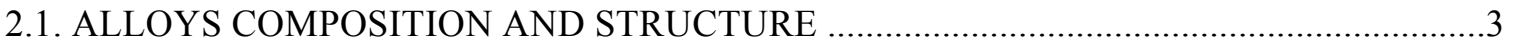

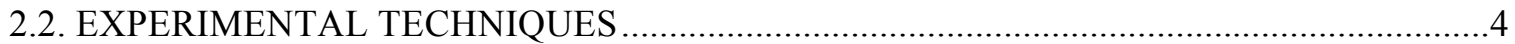

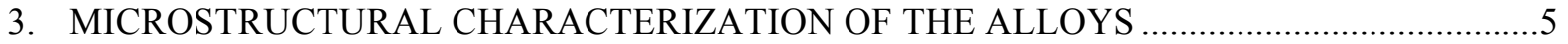

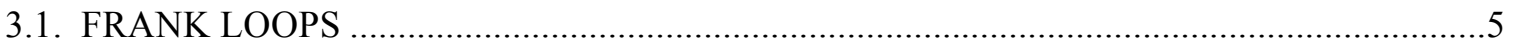

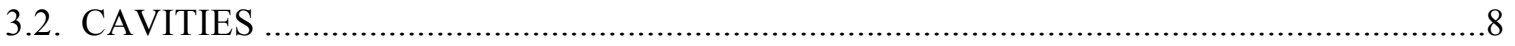

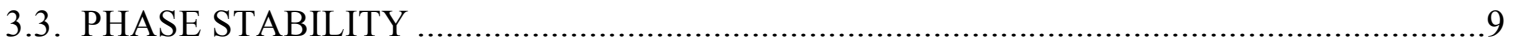

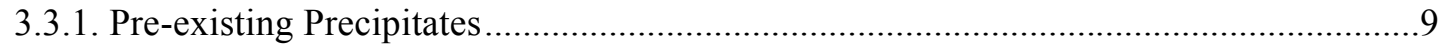

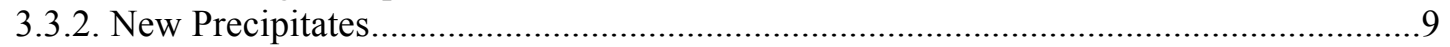

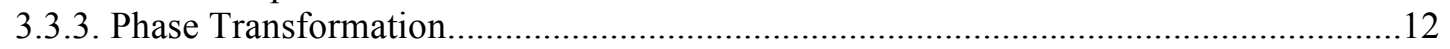

4. RADIATION INDUCED SEGREGATION (RIS) AT GRAIN BOUNDARIES ........................13

4.1. INFLUENCE OF MAJOR ALLOYING ELEMENTS ON THE RIS RESPONSE .............13

4.2. INTERPLAY BETWEEN GRAIN BOUNDARY STRUCTURE, IRRADIATION DOSE

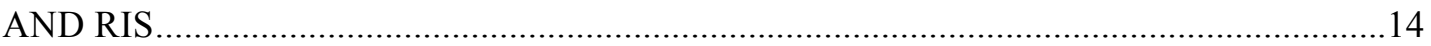

4.3. INFLUENCES OF RIS FOR ON BOUNDARY AND NEAR BOUNDARY

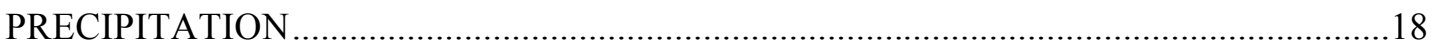

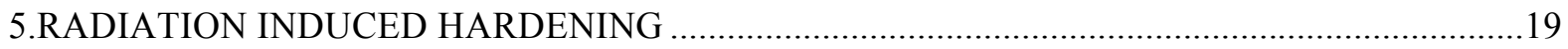

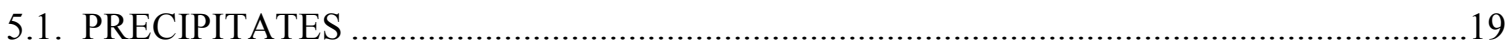

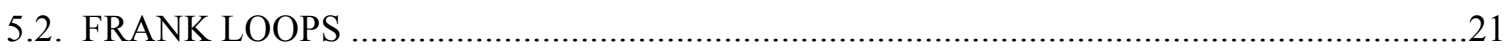

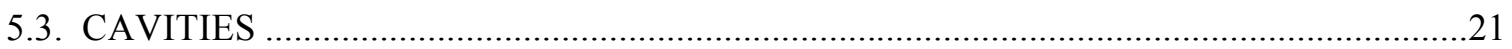

5.4. RADIATION HARDENING

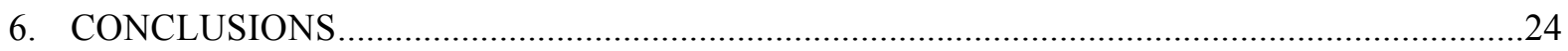

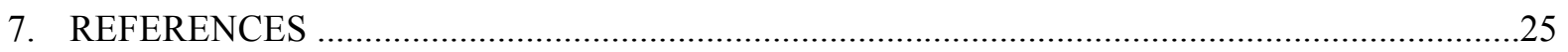


This page intentionally left blank 


\section{LIST OF FIGURES}

Figure

Page

Figure 1. Examples of a classic diffraction pattern with rel-rod configuration (left) and corresponding dark-field images showing edge-on Frank loops with the largest amount in SW37 (center) and the minimum amount in GS13 (right).

Figure 2. Statistical results ( $2 \mathrm{~nm}$ bin size) of Frank loop size distribution in the irradiated samples AS13, AS18, GS13, and SW37.

Figure 3. Alloy chemistry (equivalent $\mathrm{Cr}$ and SFE) dependence of Frank loop size and density...... 7

Figure 4. Irradiation dose dependence of Frank loop size and density. (Solid symbols -this work,

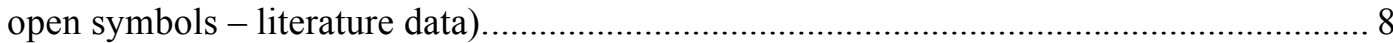

Figure 5. Irradiation dose dependence of Frank loop size and density ........................................... 8

Figure 6. $\quad \mathrm{M}_{23} \mathrm{C}_{6}(\mathrm{P})$ and Laves phases not altered by the irradiation in the analyzed samples........... 9

Figure 7. Five types of radiation-induced precipitates observed in the analyzed samples............... 11

Figure 8. Radiation dose dependent size and density of the precipitates observed in this work (solid circles - G-phase, squares - unknown randomly orientated phase, triangles $-\gamma^{\prime}$-phase) as

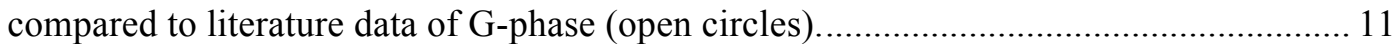

Figure 9. Three types of phase instabilities observed in the analyzed samples............................... 12

Figure 10. Measured change in $\mathrm{Cr}$ and $\mathrm{Ni}$ grain boundary concentrations as a function of bulk $\mathrm{Cr} / \mathrm{Ni}$ ratio at 9.8-11.8 dpa at $320{ }^{\circ} \mathrm{C}$ for HA grain boundaries.

Figure 11. 1D concentration profiles from A-alloy irradiated 5.5 dpa at $320^{\circ} \mathrm{C}$. (a) Experimentally determined profile of a $\Sigma 3$ grain boundary. (b) Experimentally determined profile of a HA grain boundary.

Figure 12. Average on-boundary concentrations of Ni and Si for different grain boundary types in Aalloy irradiated at varying doses at $320^{\circ} \mathrm{C}$.

Figure 13. 1D concentration profiles showing the response of $\Sigma 3$ grain boundaries (open symbols) and HA grain boundaries (closed symbols) for alloys of varying composition. (a) A-alloy, (b) K-alloy, (c) L-alloy. 17

Figure 14. Elemental EDS maps extracted from spectrum images showing the Ni-Si cluster formations near grain boundaries in A-alloy irradiated to $47.1 \mathrm{dpa}$. Grain boundaries run top to bottom of the page. (a) HA grain boundary, (b) $\Sigma 3$ grain boundary. 18

Figure 15. Strength factor $\alpha$ of Frank loops, spherical Orowan precipitates, and cavities (solid symbols -this work, open symbols - literature data).

Figure 16. Agreement between calculated and measured radiation hardening of the analyzed samples. 
This page intentionally left blank 


\section{LIST OF TABLES}

Table

Page

Table 1. Alloy composition (wt.\%) and the analyzed samples. .................................................... 3

Table 2. Size $(\mathrm{nm})$ and density $\left(\mathrm{m}^{-3}\right)$ of Frank loops observed in the analyzed samples. ................... 6

Table 3. Size $(\mathrm{nm})$ and density $\left(\mathrm{m}^{-3}\right)$ of cavities observed in the analyzed samples.......................... 9

Table 4. Size $(\mathrm{nm})$ and density $\left(\mathrm{m}^{-3}\right)$ of precipitates observed in the analyzed samples.................... 11 
This page intentionally left blank 


\section{ACKNOWLEDGMENTS}

This research was sponsored by the U.S. Department of Energy, Office of Nuclear Energy, for the Light Water Reactor Sustainability Research and Development effort.

The authors are grateful to Maxim Gussev for his management of the irradiated samples and helpful discussions and Stephanie Curlin for preparing the samples. 
This page intentionally left blank 


\section{EXECUTIVE SUMMARY}

Components serving in a nuclear reactor plant must withstand a very harsh environment including extended time at elevated temperatures, neutron irradiation, stress, and/or corrosive media. The many modes of degradation are complex and very depending on material and service locations. However, understanding and managing materials degradation is paramount for the continued safe and reliable operation of nuclear power plants. For the reactor core and primary systems, several key areas have been identified. Thermomechanical considerations such as aging and fatigue must be examined. Irradiation-induced processes must also be considered for higher fluences under the life extension consideration of the current light water reactors (LWRs), which particularly includes the influence of radiation-induced segregation (RIS), swelling, and precipitation on component hardening and embrittlement. Corrosion takes many forms within the reactor core, although irradiation-assisted stress corrosion cracking (IASCC) and primary water stress corrosion cracking (PWSCC) are of high interest in extended life scenarios. Research in these areas can build upon other ongoing programs in the LWR industry as well as other reactor materials programs (such as fusion and fast reactors) to help resolve these issues for extended LWR life.

Type 304 and 316 stainless steels are classic structural materials used in LWRs. A set of well designed type 304 and 316 variants by changing the amount of a single solute element were irradiated using the BOR- 60 fast breeder reactor at $\sim 320^{\circ} \mathrm{C}$ in Russia. This set of alloy samples has been used in this task to characterize detailed microstructural evolution and measure magnetic phase, swelling and hardness. This report summarizes the detailed microstructural results, characterized using conventional and scanning transmission electron microscopy (CTEM/STEM) and energy dispersive X-ray spectroscopy (EDS), and the newly developed model of strength factor for estimating radiation hardening. The results provide invaluable insights into understanding degradation mechanisms of key components and assists in the prediction of the life of similar materials and the base knowledge required to develop advanced radiation resistant alloys. The effect of solute elements on microstructural evolution under neutron irradiation is explored. The approximate correlation between microstructure changes and radiation hardening is established. The major results and implications are discussed below.

A total of eleven irradiated samples from nine alloys have been characterized. Frank loops and ultrafine precipitates are major features observed in these samples. Additionally, a few ultrafine cavities were observed in most of analyzed samples, which have not been reported in the studies on similar alloys irradiated at the same or similar conditions. It was found that the size of Frank loops slightly increases with higher equivalent $\mathrm{Cr}$ content and the density decreases with higher stacking fault energy of the alloys. The irradiation did not alter the pre-existing $\mathrm{M}_{23} \mathrm{C}_{6}(\mathrm{M}=\mathrm{Cr}$-rich) and Laves phases, but introduced nano-scale $\mathrm{M}_{23} \mathrm{C}_{6}$ and noticeable amounts of ultrafine G-phase, $\gamma$ 'phase, and unknown phases in $\mathrm{L} 1_{2}$ and $\alpha^{\prime}$ (Cr-rich) structures in different samples. Phase transformations with the formation of $\alpha$-ferrite, $\varepsilon^{\prime}$-martensite, and possible $\mathrm{CrC}$ phases were observed in three of the samples. Higher radiation dose tends to increase the size but decrease the density of Frank loops and precipitates in different levels. Due to the limited amount of cavities observed in the samples, their relationship with alloy chemistry and radiation dose was not able to be determined.

A subset of specimens was investigated for radiation-induced segregation (RIS). It was found the segregation response is dependent on the bulk alloy composition. Increasing the $\mathrm{Cr} / \mathrm{Ni}$ ratio of the bulk concentration decreased the change in Ni concentration at the boundary, but the change in $\mathrm{Cr}$ concentration dependency was more complex with a minimum change seen near $\mathrm{Cr} / \mathrm{Ni}$ ratios around 1.0. Grain boundary structure (or type of grain boundary) was found to also strongly influence the 
RIS response across all alloys and doses investigated, with $\Sigma 3$ grain boundaries completely suppressing the RIS response. The structure dependence was found to be independent of composition or damage dose. Initial work indicates the compounding factors of damage dose, grain boundary structure, and local composition could also impact the formation of Ni-Si clusters in the vicinity of grain boundaries in alloys with sufficient Si contents.

The generally accepted dispersed barrier hardening model was used to estimate radiation hardening. However, the strength factor $(\alpha)$ in the hardening model is not well defined, which is usually obtained by approximation from references or back-calculation from measured strength of irradiated samples. To be able to directly estimate radiation hardening, a model of strength factor was developed in this work in the form of $\alpha=\mathrm{k}_{1} \times \ln \left(\mathrm{k}_{2} \times d\right)$ with $d$ for the size of Frank loops, precipitates and cavities, where $\mathrm{k}_{1}$ and $\mathrm{k}_{2}$ are fitting parameters. The calculated radiation hardening results using the strength factor model and the dispersed barrier hardening model are in good agreement with experimental results. 


\section{BACKGROUND}

Nuclear power currently provides a significant fraction of the United States' non-carbon emitting power generation. In future years, nuclear power must continue to generate a significant portion of the nation's electricity to meet the growing electricity demand, clean energy goals, and ensure energy independence. New reactors will be an essential part of the expansion of nuclear power. However, given limits on new builds imposed by economics and industrial capacity, the extended service of the existing fleet will also be required.

Nuclear reactors present a very harsh environment for components service. Components within a reactor core must tolerate high temperature water, stress, vibration, and an intense neutron field. The nominal irradiation temperature in light water reactors (LWRs) is $\sim 290^{\circ} \mathrm{C}$; however, actual component temperatures range from $270^{\circ} \mathrm{C}$ to $370^{\circ} \mathrm{C}$ depending on the relative position of the component within the reactor core and relative amounts of cooling and gamma heating. Degradation of materials in this environment can lead to reduced performance, and in some cases, sudden failure.

Extending the service life of a reactor will increase the total neutron fluence to each component and may result in irradiation-induced effects not yet observed in LWR conditions, although this form of degradation has been observed in fast reactor conditions. Irradiation-induced processes must be carefully considered for higher fluences, particularly the influence of radiation-induced segregation (RIS), swelling, and/or precipitation on embrittlement. The neutron irradiation field can produce large property and dimensional changes in materials. This occurs primarily via one of five radiation damage processes: radiation-induced hardening and embrittlement, phase instabilities from radiationinduced or -enhanced segregation and precipitation, irradiation creep due to unbalanced absorption of interstitials vs. vacancies at dislocations, volumetric swelling from cavity formation, and high temperature helium embrittlement due to formation of helium-filled cavities on grain boundaries. For LWRs, high temperature embrittlement and creep are not common problems due to the lower reactor temperature. However, radiation embrittlement, phase transformation, segregation, and swelling have all been observed in reactor components. Therefore, radiation-induced phase transformations, hardening, and segregation are focused in this work.

Under irradiation, the large concentrations of radiation-induced defects will diffuse to defect sinks such as grain boundaries and free surfaces. These concentrations are in far excess of thermalequilibrium values and can lead to coupled-diffusion with particular atoms. In engineering metals such as stainless steel, this results in RIS of elements within the steel. For example, in type 316 stainless steel, chromium (important for corrosion resistance) can be depleted at areas while elements like nickel and silicon are enriched to levels well above the starting, homogenous composition. While RIS does not directly cause component failure, it can influence corrosion behavior in a water environment. Irradiation-induced changes of alloy microstructure may also lead to hardening and susceptibility to mechanical failure. Further, this form of degradation can accelerate the thermallydriven phase transformations and also result in phase transformations that are not favorable under thermal aging. Phase transformations have been observed in a variety of materials and operating conditions of austenitic steels in LWRs that may impact component lifetime as plants strive towards longer lifetimes. This form of degradation may become visible in a number of components including core barrels, baffle plates, baffle bolts, top guides, and support plates. All of these components are made from austenitic stainless steels including 304, 316, and 347 grades. Of these grades, 316 may be the most susceptible to the formation of $\mathrm{G}$ and $\gamma^{\prime}$ phases due to the higher Ni content. 304 and 347 may be more likely to undergo martensitic transformations due to their lower austenite stability. Additional fluence may exacerbate radiation-induced phase transformations and should be considered. 
Under the LWRS Materials Aging and Degradation Pathway, a research task of providing detailed microstructural analysis of phase transformation in key samples and components (both model alloys and service materials) was initiated in FY 2012. This task includes the measurements of magnetic phase, swelling and hardness of the samples and detailed microstructural characterization using transmission electron microscopy. This report summarizes the microstructural characterization results and the developed calculation method for estimating radiation hardening. These results will be used to develop and validate phenomenological models of phase transformation and RIS under LWR conditions, which is being studied under another research task. 


\section{EXPERIMENTAL PROCEDURES AND MATERIALS}

\subsection{ALLOYS COMPOSITION AND STRUCTURE}

A set of well-selected alloy samples was used in this work. The alloy identification letters, compositions, and analyzed samples are listed in Table 1. Based on the high purity (HP) 304 stainless steel (alloy E), a series of model alloys were prepared by alloying different elements, such as Mo in alloy $\mathrm{G},(\mathrm{Mo}+\mathrm{Hf})$ in alloy $\mathrm{P}, \mathrm{Ti}$ in alloy $\mathrm{M}, \mathrm{Nb}$ in alloy $\mathrm{N}, \mathrm{Ni}$ in alloy $\mathrm{K},(\mathrm{Ni}+\mathrm{Cr})$ in alloy $\mathrm{L}, \mathrm{Si}$ in alloy $\mathrm{H}, \mathrm{P}$ in alloy $\mathrm{I}$, and reduced $\mathrm{C}$ in alloy F. Industrial 304 stainless steel from core shroud (alloy A) and control rod blade (alloy SW), together with cold worked (CW) 316 stainless steel (alloy B) and 316+Ti (alloy C) from baffle bolt, are included for comparison. The analyzed alloy samples were irradiated in the BOR-60 reactor to $11.8 \mathrm{dpa}$ (displacement per atom) with a dose rate of $\sim 8 \times 10^{-7} \mathrm{dpa} / \mathrm{s}$ at $\sim 320^{\circ} \mathrm{C}$. The samples of alloys $\mathrm{M}$ and $\mathrm{N}$ were secured by the time of the report, which will be analyzed in the same manner of the analyzed samples. The samples of alloys I, H and C were not studied in this project.

Table 1. Alloy composition (wt.\%) and the analyzed samples.

\begin{tabular}{cccccccccccccc}
\hline $\begin{array}{c}\text { Alloy } \\
\text { ID }\end{array}$ & Remark & $\mathbf{C}$ & $\mathbf{M n}$ & $\mathbf{S i}$ & $\mathbf{C r}$ & $\mathbf{N i}$ & $\mathbf{M o}$ & $\mathbf{N b}$ & $\mathbf{T i}$ & $\mathbf{H f}$ & $\mathbf{P}$ & $\begin{array}{c}\text { Sample } \\
\text { ID }\end{array}$ & $\begin{array}{c}\text { Dose } \\
\text { (dpa) }\end{array}$ \\
\hline & & & & & & & & & & & & AS13 & 5.5 \\
$\mathbf{A}$ & Ind. 304 & 0.023 & 1.82 & 0.56 & 19.95 & 10.8 & 0.53 & $<0.001$ & 0.02 & - & 0.023 & AS18 & 10.2 \\
& & & & & & & & & & & & AS23 & 47.1 \\
$\mathbf{S W}$ & Ind. 304 & 0.022 & 1.07 & 0.24 & 18.42 & 10.45 & - & - & - & - & 0.015 & SW37 & 4.4 \\
$\mathbf{E}$ & HP304 & 0.021 & 0.94 & 0.04 & 18.76 & 12.37 & 0.04 & - & 0.01 & - & $<0.01$ & ES13 & 11.8 \\
$\mathbf{F}$ & $\mathbf{E}-\mathrm{C}$ & $\mathbf{0 . 0 0 8}$ & 0.98 & 0.03 & 18.17 & 12.06 & 0.02 & 0.005 & 0.01 & - & $<0.01$ & $\mathrm{FS} 13$ & 9.1 \\
$\mathbf{G}$ & $\mathbf{E}+\mathrm{Mo}$ & 0.02 & 0.97 & 0.03 & 18.26 & 12.15 & $\mathbf{2 . 3 6}$ & 0.002 & 0.01 & - & $<0.01$ & $\mathrm{GS} 13$ & 11.8 \\
$\mathbf{H}$ & $\mathbf{E}+\mathrm{Si}$ & 0.02 & 1.01 & $\mathbf{1 . 0 5}$ & 18.17 & 12.45 & 0.02 & $<0.001$ & 0.01 & - & $<0.01$ & & \\
$\mathbf{I}$ & $\mathbf{E}+\mathrm{P}$ & 0.007 & 1.01 & 0.03 & 18.21 & 12.11 & 0.02 & $<0.001$ & 0.01 & - & $\mathbf{0 . 0 1 6}$ & & 4.4 \\
$\mathbf{K}$ & $\mathbf{E}+\mathrm{Ni}$ & 0.02 & 1 & 0.03 & 18.21 & $\mathbf{2 5 . 0 8}$ & 0.02 & $<0.001$ & 0.01 & - & $<0.01$ & $\mathrm{KS} 13$ & 9.6 \\
$\mathbf{L}$ & $\mathbf{E}+\mathrm{Ni}+\mathrm{Cr}$ & 0.02 & 1.02 & 0.03 & $\mathbf{2 5 . 2 2}$ & $\mathbf{2 5 . 0 7}$ & 0.02 & $<0.001$ & 0.01 & - & $<0.01$ & LS13 & 9.1 \\
$\mathbf{M}$ & $\mathbf{E}+\mathrm{Ti}$ & 0.02 & 1 & 0.03 & 18.03 & 11.22 & 0.02 & $<0.001$ & $\mathbf{0 . 3}$ & - & $<0.01$ & MS01" & 10.7 \\
$\mathbf{N}$ & $\mathbf{E}+\mathrm{Nb}$ & 0.02 & 1 & 0.03 & 18.24 & 12.12 & 0.02 & $\mathbf{0 . 5 9 5}$ & 0.01 & - & $<0.01$ & NS01" & 10.7 \\
$\mathbf{P}$ & $\mathbf{E}+\mathrm{Mo}+\mathrm{Hf}$ & 0.028 & 1.01 & 0.1 & 17.03 & 13.6 & $\mathbf{2 . 1 8}$ & - & - & $\mathbf{1 . 1 7}$ & 0.01 & $\mathrm{PS} 15$ & 9.6 \\
$\mathbf{B}$ & Ind. 316 & 0.056 & 1.13 & 0.73 & 16.84 & 10.54 & 2.25 & 0.008 & 0.01 & - & 0.022 & $\mathrm{BS} 13$ & 5.5 \\
$\mathbf{C}$ & Ind. 316 & 0.07 & 1.4 & 0.56 & 16.77 & 12.78 & 2.18 & $<0.01$ & 0.38 & - & 0.013 & BS16 & 10.2 \\
\hline
\end{tabular}

Note: Except for the industrial alloys with up to $0.29 \% \mathrm{Cu}, 0.22 \% \mathrm{Co}, 0.072 \% \mathrm{~N}$, and $0.022 \% \mathrm{~S}$, the others are reported with $<0.01 \% \mathrm{Cu}, 0.01 \% \mathrm{Co},<0.0005 \% \mathrm{~N}$, and $<0.007 \% \mathrm{~S}$. The alloys $\mathrm{E}, \mathrm{F}, \mathrm{G}, \mathrm{B}$, and $\mathrm{C}$ are in $\mathrm{CW}$ condition. All the other alloys are in annealed condition.

The alloys were annealed and water quenched condition prior to the neutron irradiation. However, analyses of the nonirradiated and irradiated samples suggested that alloys B, C, E, F and G were subjected to different levels of cold work $(\varepsilon)$, e.g., alloy B with $\sim 0.6, \mathrm{C}$ with $\sim 0.4$, and $\mathrm{E}$ and $\mathrm{G}$ with $\sim 0.3$ [1]. The analyzed samples in the present work were cut off from the ends of tensile dog bone specimens. It is assumed that tensile testing did not exert any changes to the materials in this region of the samples. 


\subsection{EXPERIMENTAL TECHNIQUES}

Material microstructures were characterized using transmission electron microscopy (TEM) techniques on a FEI CM200 field-emission-gun (FEG) TEM. Three-mm diameter discs were sectioned from the tab section of tensile samples, ground down to $<\sim 150 \mu \mathrm{m}$ thickness. Then, the samples were electro-polished at $-12^{\circ} \mathrm{C}$ in a methanol: sulfuric $(7: 1)$ solution using a Struers Tenupol polishing unit. A range of magnifications was used to record the microstructures at different length scales. The characterization included phase identification, grain boundary chemical analysis, and statistical quantitative analysis of the radiation-induced Frank loops and possible voids. Specimen thickness was estimated using convergent beam electron diffraction (CBED). Conventional TEM and scanning transmission electron microscopy (STEM) modes coupled with selected area diffraction (SAD) and energy dispersive X-ray spectroscopy (EDS) were used in this work to characterize morphology, identify phase and chemistry.

Radiation-induced segregation (RIS) in the samples was investigated using STEM-EDS spectrum imaging techniques. Spectrum images were taken with a $50 \mathrm{~nm} \times 50 \mathrm{~nm}$ region-of-interest using $25 \times$ 25 pixels with the grain boundary orientated running top to bottom in the image. An incident probe size of $1.5 \mathrm{~nm}$ with $\sim 1 \mathrm{nA}$ of probe current was used and acquisition was taken with 1.5 second dwell times and a drift correction every 19 pixels. Quantification of elements was completed using the Cliff-Lorimer quantification scheme. Experimentally determined ' $\mathrm{k}$ ' factors were quantified assuming a normalized alloy composition. Spectrum images were binned parallel to the boundary to increase counting statistics and provide an average 1D profile along the length of the grain boundary. Average profiles were fitted to a single Gaussian peak to determine peak height and profile FWHM. Error bars are reported using one standard deviation of the mean through binning.

All grain boundaries were characterized based on grain boundary misorientation angle and axis. Grain boundary parameters were determined using diffracted Kikuchi patterns of each grain comprising a grain boundary immediately following EDS acquisition. Patterns were indexed assuming a face-centered cubic (fcc) grain boundary structure at a calibrated camera length of 119 $\mathrm{mm}$ at the CCD using custom software [2]. Calculated misorientation angle/axis pairs were used to classify the grain boundary types as either low angle grain boundaries, general high angle grain boundaries, or low $-\Sigma(<\Sigma 27)$ coincident site lattice $(\mathrm{CSL})$ grain boundaries using the Brandon criteria [3]. 


\section{MICROSTRUCTURAL CHARACTERIZATION OF THE ALLOYS}

Frank loops, cavities, and precipitates have been the primarily characterized defects in the analyzed alloy samples.

\subsection{FRANK LOOPS}

Frank loops are common radiation-induced defects in austenitic steels. An example of the diffraction condition used to image edge-on Frank loops is shown in Figure 1 (left). The diffraction condition was obtained by tilting $\sim 8^{\circ}$ away from the [011] zone axis along the $g=311$ reflection. The near [011] zone axis condition gives two edge-on variants, exhibiting as rel-rods due to the presence of the $\{111\}$ stacking faults in the loop variants. Although some of the edge-on loops were viewable in bright-field (BF) imaging condition, their contrast was too low to easily conduct statistical analysis. Therefore, dark-field (DF) imaging condition was employed by using one of the four variants of relrods, e.g., the encircled rel-rod in Figure 1 (left). Figure 1 (center and right) shows the examples of edge-on Frank loops in the samples of SW37 and GS13, exhibiting the largest and minimum amounts of Frank loops, respectively, among the analyzed samples.
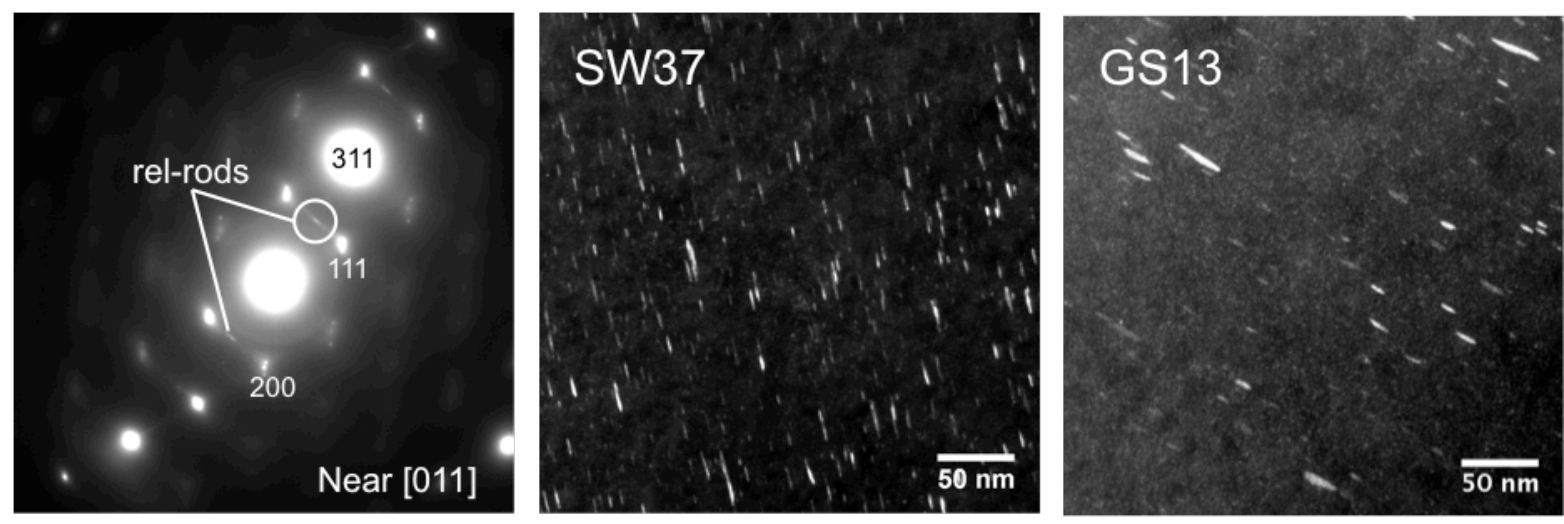

Figure 1. Examples of a classic diffraction pattern with rel-rod configuration (left) and corresponding dark-field images showing edge-on Frank loops with the largest amount in SW37 (center) and the minimum amount in GS13 (right).

The statistical loop size distributions in the samples of GS13, SW37, AS13, and AS18 are plotted in Figure 2. The data can be well fitted using an extreme function of $y=y_{0}+\operatorname{Aexp}\left\{-\exp \left[-\left(x-x_{\mathrm{c}}\right) / \mathrm{w}\right]-(x\right.$ $\left.\left.-x_{\mathrm{c}}\right) / \mathrm{w}+1\right\}$ with $y_{0}$ for profile offset and $x_{\mathrm{c}}, \mathrm{w}$, and A for peak center, width, and amplitude, respectively. The size distributions of AS13 and AS18 suggest that higher irradiation damage (dpa) tends to broaden the distribution peak with smaller amplitude (frequency) and shift it to larger loop size. As compared to SW37, in contrast, the higher irradiation damage in GS13 only exhibited larger loop size but similar frequency and distribution width, which suggest that alloy chemistry may have played an important role on the size distribution. 


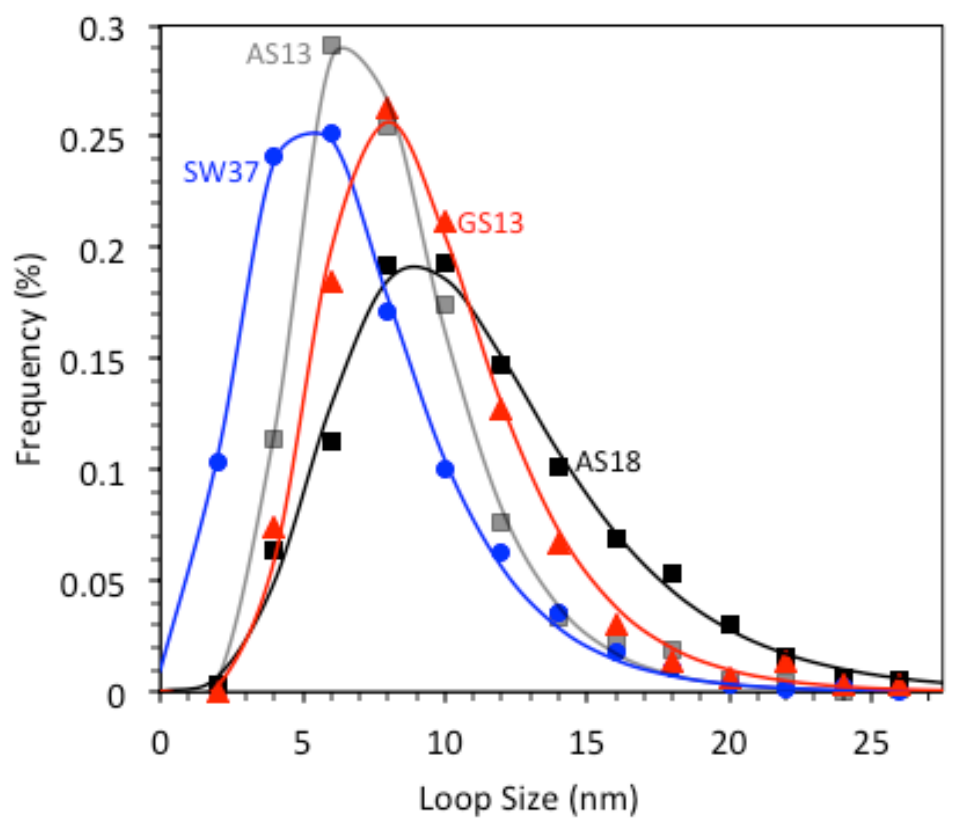

Figure 2. Statistical results ( $2 \mathrm{~nm}$ bin size) of Frank loop size distribution in the irradiated samples AS13, AS18, GS13, and SW37.

The statistically analyzed size and density of the Frank loops developed in the irradiated samples are summarized in Table 2. The standard deviations of loop sizes are very large, which are about $1 / 2$ of their corresponding averages. At least three DF images of edge-on Frank loops at different sample locations were captured to obtain density deviations that are about one order of magnitude lower than the averages on the order of $10^{22}-10^{23} \mathrm{~m}^{-3}$.

Table 2. Size (nm) and density $\left(\mathrm{m}^{-3}\right)$ of Frank loops observed in the analyzed samples.

\begin{tabular}{ccc}
\hline Sample & Size & Density,$\times 10^{22}$ \\
\hline AS13 & $7.35 \pm 3.36$ & $10.6 \pm 1.21$ \\
AS18 & $10.1 \pm 4.68$ & $8.46 \pm 0.71$ \\
BS13 & $8.00 \pm 4.31$ & $5.41 \pm 1.37$ \\
BS16 & $9.18 \pm 4.20$ & $4.43 \pm 0.24$ \\
ES13 & $9.14 \pm 4.45$ & $2.56 \pm 0.43$ \\
FS13 & $6.36 \pm 3.46$ & $6.33 \pm 0.68$ \\
GS13 & $8.53 \pm 3.74$ & $2.29 \pm 0.22$ \\
KS13 & $9.33 \pm 4.61$ & $4.82 \pm 0.68$ \\
LS13 & $8.80 \pm 4.53$ & $5.13 \pm 0.36$ \\
PS15 & $8.38 \pm 4.16$ & $2.95 \pm 0.65$ \\
SW37 & $5.92 \pm 3.57$ & $13.5 \pm 1.85$ \\
\hline
\end{tabular}

The effect of alloy chemistry on the size and density of Frank loops was analyzed using equivalent $\mathrm{Cr}$ $\left(\mathrm{Cr}_{\mathrm{eq}}\right)$, equivalent $\mathrm{Ni}\left(\mathrm{Ni}_{\mathrm{eq}}\right)$, and stacking fault energy (SFE). The following equations were used to estimate the three alloy chemistry dependent parameters with the elements as their corresponding wt.\% in the alloys: 


$$
\begin{aligned}
& \mathrm{Cr}_{\text {eq }}(\mathrm{wt} . \%)=\mathrm{Cr}+2 \mathrm{Si}+1.5 \mathrm{Mo}+5 \mathrm{~V}+5.5 \mathrm{Al}+1.75 \mathrm{Nb}+1.5 \mathrm{Ti}+0.75 \mathrm{~W} \\
& \mathrm{Ni}_{\text {eq }}(\text { wt. } \%)=30 \mathrm{C}+0.5 \mathrm{Mn}+\mathrm{Ni}+25 \mathrm{~N}+\mathrm{Co}+0.3 \mathrm{Cu} \\
& \text { SFE }(\mathrm{J})=39+1.59 \mathrm{Ni}-1.34 \mathrm{Mn}+0.06 \mathrm{Mn}^{2}-1.75 \mathrm{Cr}+0.01 \mathrm{Cr}^{2}+15.21 \mathrm{Mo}-5.59 \mathrm{Si} \\
& -60.69 \sqrt{ }(\mathrm{C}+1.2 \mathrm{~N})+26.27(\mathrm{C}+1.2 \mathrm{~N}) \sqrt{ }(\mathrm{Cr}+\mathrm{Mn}+\mathrm{Mo})+0.61 \sqrt{ }(\mathrm{Ni}(\mathrm{Cr}+\mathrm{Mn}))
\end{aligned}
$$

Relationships were mainly found on the $\mathrm{Cr}_{\text {eq }}$ dependent loop size and the SFE dependent loop density as shown in Figure 3. The letter in each circle denotes the corresponding alloy. Higher $\mathrm{Cr}_{\mathrm{eq}}$ tends to slightly increase loop size and higher SFE tends to decrease loop density.
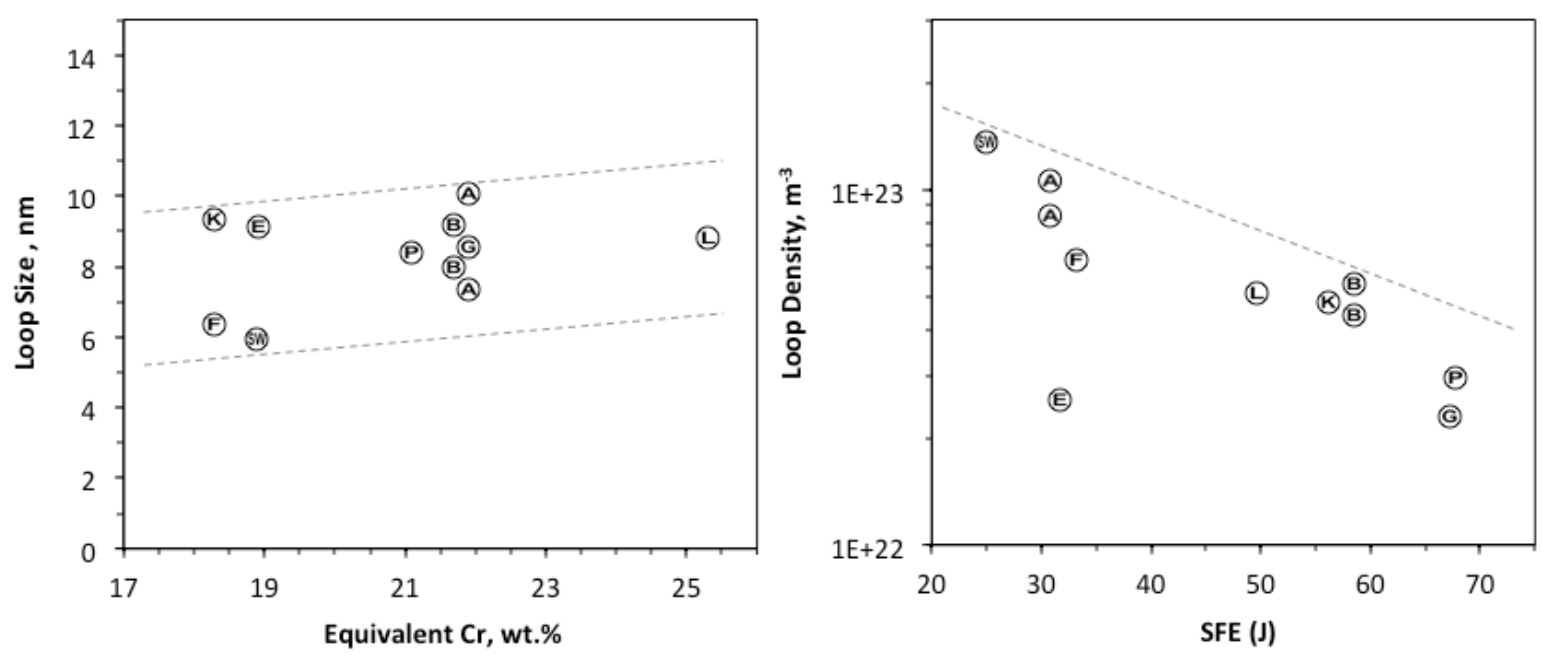

Figure 3. Alloy chemistry (equivalent $\mathrm{Cr}$ and SFE) dependence of Frank loop size and density.

The measured loop sizes and densities are compared to literature data of similar alloys irradiated at the same or similar conditions [4-9]. The comparison results are summarized in Figure 4, indicating a good agreement between this work and the literature. The loop size shows a slight increase with higher radiation damage. Only one data point had an extremely larger loop size of $25.5 \mathrm{~nm}$, which was measured in a 304 variant with reduced amount of sulfur (S) [7]. In contrast, the loop density appears to decrease with the increase of radiation damage. 

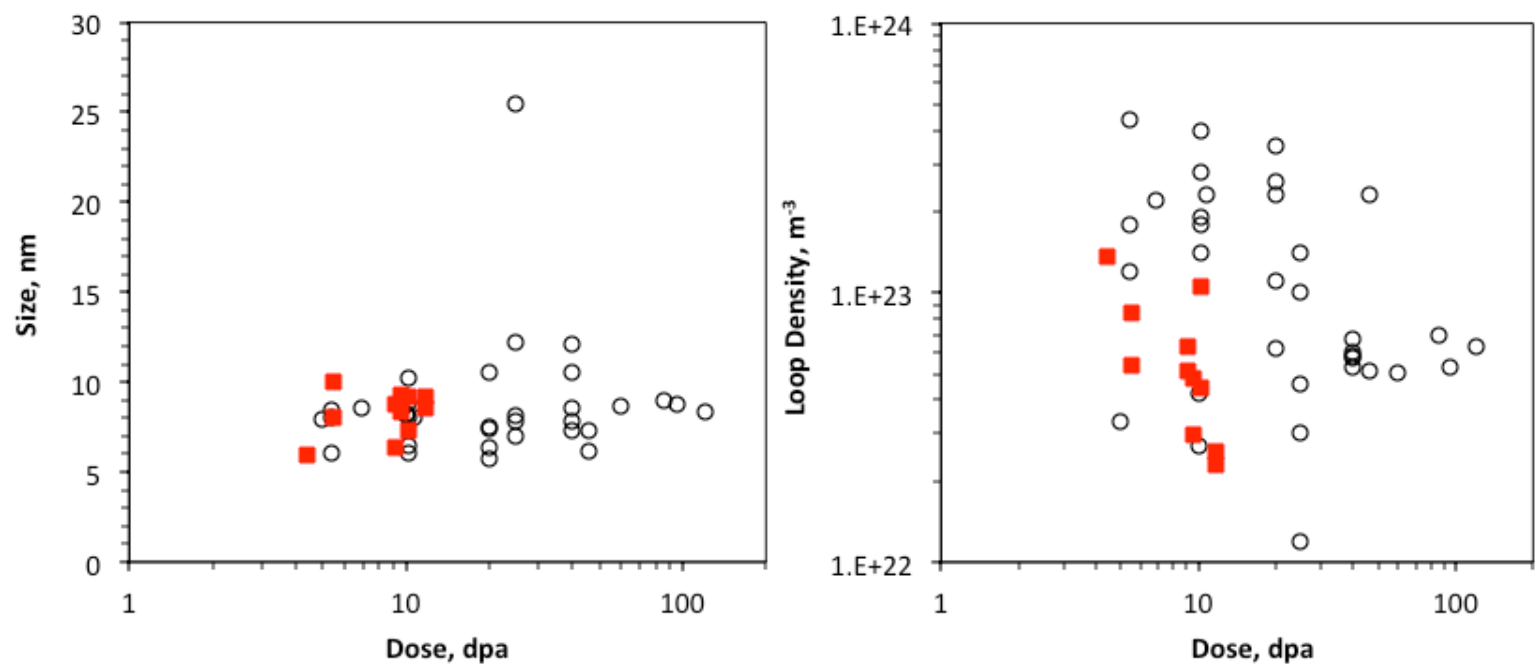

Figure 4. Irradiation dose dependence of Frank loop size and density. (Solid symbols -this work, open symbols - literature data).

\subsection{CAVITIES}

Radiation-induced cavities were observed in most of the analyzed samples using the under-focus BF imaging condition. Their amounts are significantly less than Frank loops. Figure 5 shows examples of observed cavities in the samples of KS13 and BS16. Most of the observed cavities are very small with a size of $\sim 2 \mathrm{~nm}$, as pointed with black arrows in Figure 5 (KS13). Larger cavities were occasionally observed in a few of the analyzed samples, e.g., Figure 5 (BS16). The analyzed sizes and densities of the cavities are summarized in Table 3. The estimated density of cavities is not as reliable as that of Frank loops because high magnifications had to be used to visualize the cavities, resulting in the limited numbers within a small area. Cavities were not observed in the samples of ES13, LS13, PS15, and SW37. However, it cannot be conclusively determined if these samples have ultrafine cavities which could be lower than the detection limits of the TEM system used here.
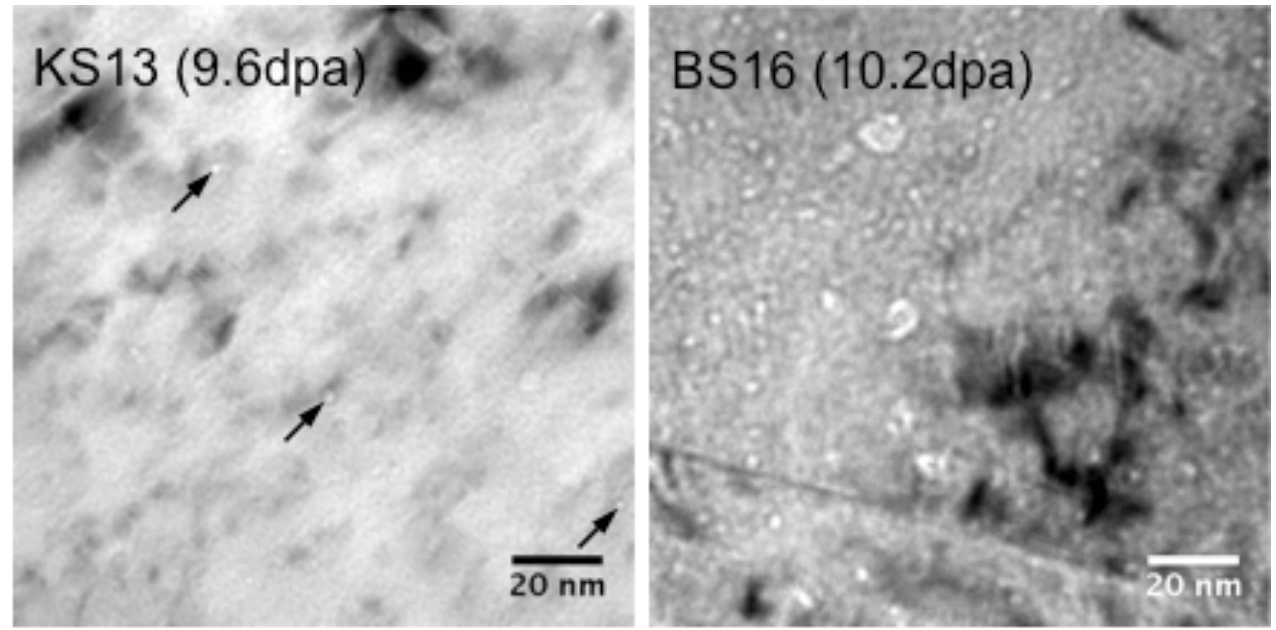

Figure 5. Irradiation dose dependence of Frank loop size and density. 
Table 3. Size (nm) and density $\left(\mathrm{m}^{-3}\right)$ of cavities observed in the analyzed samples.

\begin{tabular}{ccc}
\hline Sample & Size & Density,$\times 10^{21}$ \\
\hline AS13 & $1.96 \pm 0.08$ & 8.01 \\
AS18 & $2.31 \pm 0.97$ & 32.8 \\
BS13 & $2.73 \pm 0.62$ & 4.86 \\
BS16 & $4.34 \pm 1.14$ & 22.2 \\
ES13 & - & - \\
FS13 & $2.28 \pm 0.95$ & 19.5 \\
GS13 & 9.93 & 0.27 \\
KS13 & $3.85 \pm 1.34$ & 1.73 \\
LS13 & - & - \\
PS15 & - & - \\
SW37 & - & - \\
\hline
\end{tabular}

\subsection{PHASE STABILITY}

\subsubsection{Pre-existing Precipitates}

Two types of pre-existing precipitates, i.e., $\mathrm{M}_{23} \mathrm{C}_{6}$ and Laves phase as shown in Figure 6, were observed in the samples of KS13 and PS15, respectively. The crystallinity of the respective precipitates was not altered by the irradiation.
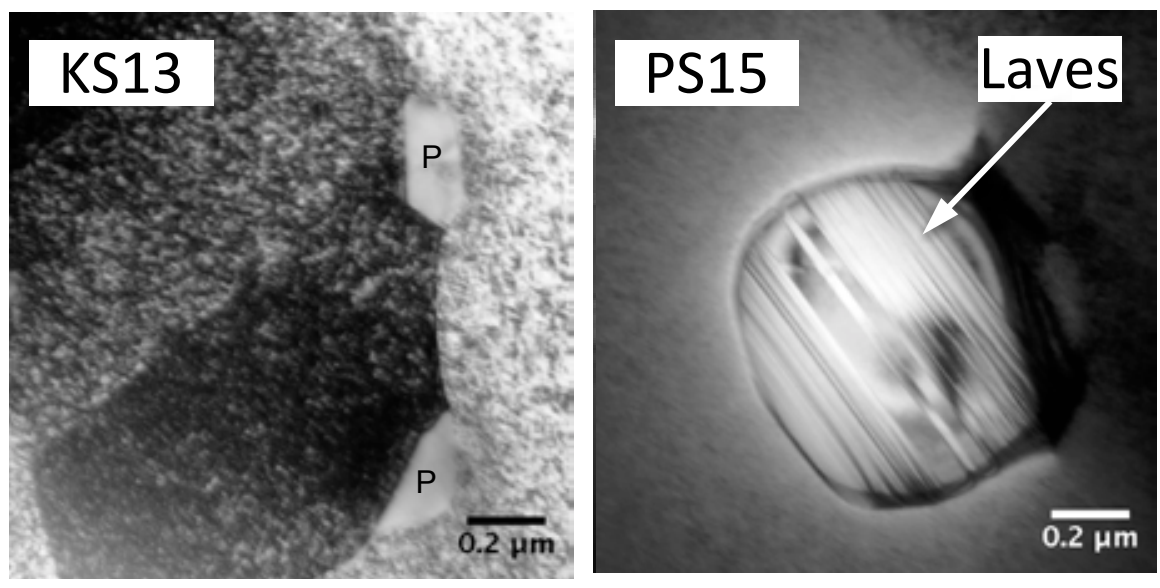

Figure 6. $M_{23} C_{6}(P)$ and Laves phases not altered by the irradiation in the analyzed samples.

\subsubsection{New Precipitates}

Five types of new precipitates were observed in the analyzed samples, three of which are cubic-oncubic well aligned with the face-centered-cubic matrix and the other two are randomly orientated precipitates. Typical morphologies and distributions of the precipitates are shown in Figure 7 in dark field images that were obtained by using their selected area diffraction reflections (inset). 
Nano-scale $\mathrm{M}_{23} \mathrm{C}_{6}$ particles, e.g., the P-labeled particle, were observed in LS13 that was alloyed with additional $\sim 6.5 \mathrm{wt} . \% \mathrm{Cr}$ as compared to HP304 (alloy E). However, the numbers of such particles were too limited to yield a reliable density.

The second type is G-phase as shown in Figure 7 as a large number of ultrafine spherical particles. As compared to $\mathrm{M}_{23} \mathrm{C}_{6}$, G-phase has the same space group of Fm-3m but a slightly larger lattice parameter, i.e., $\sim 1.11 \mathrm{~nm}$ of G-phase vs. $\sim 1.08 \mathrm{~nm}$ of $\mathrm{M}_{23} \mathrm{C}_{6}$. Similar to the inset of $\mathrm{M}_{23} \mathrm{C}_{6}$, the $\operatorname{dim}$ fine reflections in the inset were generated from the G-phase. The similarity in crystal structure results in difficulty in differentiating G-phase from $\mathrm{M}_{23} \mathrm{C}_{6}$. However, Edwards et al. [4] identified $\mathrm{M}_{23} \mathrm{C}_{6}$ in alloy $\mathrm{E}$ according to its smaller lattice parameter of $\sim 1.08 \mathrm{~nm}$. In this work, $\mathrm{M}_{23} \mathrm{C}_{6}$ was not identified in alloy $\mathrm{E}$ due to the inconclusive lattice parameter determination and similar particle size as compared to G-phase. G-phase has been observed in many of the analyzed samples, such as AS13, AS18, ES13, KS13, and LS13.

The third type is $\gamma^{\prime}$-phase that was only observed in the samples of BS13 and BS16. Unlike G-phase or $\mathrm{M}_{23} \mathrm{C}_{6}$ having $\sim 1 / 3$ spacing of the matrix reflections, the reflection of $\gamma^{\prime}$-phase has $\sim 1 / 2$ spacing of the (220) matrix reflection as shown in the inset, which is pointed with a black arrow. The $\gamma^{\prime}$-phase particles have similar size as G-phase.

The randomly orientated precipitates produced diffraction rings, suggesting their ultrafine size, which were observed in most of the analyzed samples. Most of the ring patterns could be fitted with a $\mathrm{L} 1_{2}$ structure, except for the ring pattern being fitted with a body-centered-cubic (bcc) structure in the sample of FS13. The reduced amount of carbon in FS13 may have increased the formation tendency of $\alpha$ '-phase, a Cr-rich bcc phase.
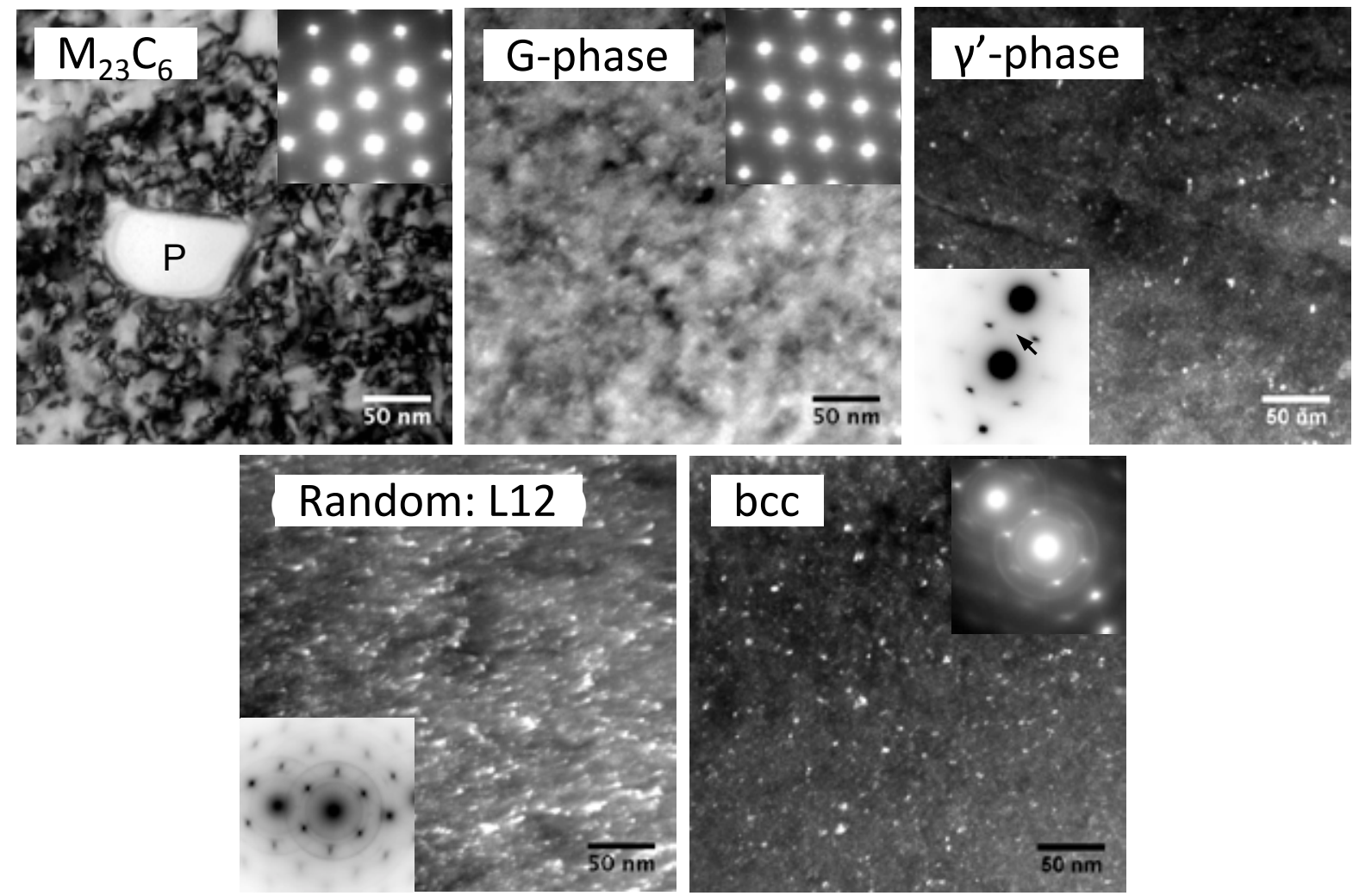
Figure 7. Five types of radiation-induced precipitates observed in the analyzed samples.

The statistically analyzed particle size and density of G-phase, $\gamma$ '-phase, and the randomly orientated unknown precipitates are summarized in Table 4. The data are plotted in Figure 8 as a function of radiation dose. The literature data [4,5,9] of G-phase are included for comparison. Overall, the particle size increases with higher radiation dose. The particle density does not show clear trend, although it is expected to decrease with increasing dose. For the same alloys A and E irradiated at the same conditions, the results of this work have slightly smaller size and density than the literature $[4,5]$.

Table 4. Size (nm) and density $\left(\mathrm{m}^{-3}\right)$ of precipitates observed in the analyzed samples.

\begin{tabular}{ccccccc}
\hline \multirow{2}{*}{ Sample } & \multicolumn{2}{c}{ G-phase } & \multicolumn{2}{c}{ Unknown } & \multicolumn{2}{c}{$\gamma^{\prime}$-phase } \\
\cline { 2 - 7 } & Size & Density, $\times 10^{21}$ & Size & Density, $\times 10^{21}$ & Size & Density, $\times 10^{21}$ \\
\hline AS13 & $4.85 \pm 0.88$ & 9.44 & $4.70 \pm 1.23$ & 2.99 & & \\
AS18 & $3.55 \pm 0.50$ & 7.61 & & & $2.12 \pm 0.86$ & $21.3 \pm 4.25$ \\
BS13 & & & $2.48 \pm 1.03$ & 33.9 & $3.04 \pm 1.07$ & 6.84 \\
BS16 & & & 1.66 & 5.78 & & \\
ES13 & $4.53 \pm 1.31$ & $8.84 \pm 0.25$ & $2.67 \pm 0.94$ & $13.9 \pm 0.98$ & & \\
FS13 & & & $2.05 \pm 0.92$ & $41.8 \pm 1.18$ & & \\
GS13 & & & $2.25 \pm 0.83$ & 12.1 & & \\
KS13 & $4.66 \pm 0.69$ & 11.3 & $3.05 \pm 1.25$ & 8.48 & & \\
LS13 & $5.76 \pm 1.04$ & 8.65 & $2.20 \pm 0.64$ & 172 & & \\
PS15 & & & 2.25 & & & \\
SW37 & & & & & & \\
\hline
\end{tabular}
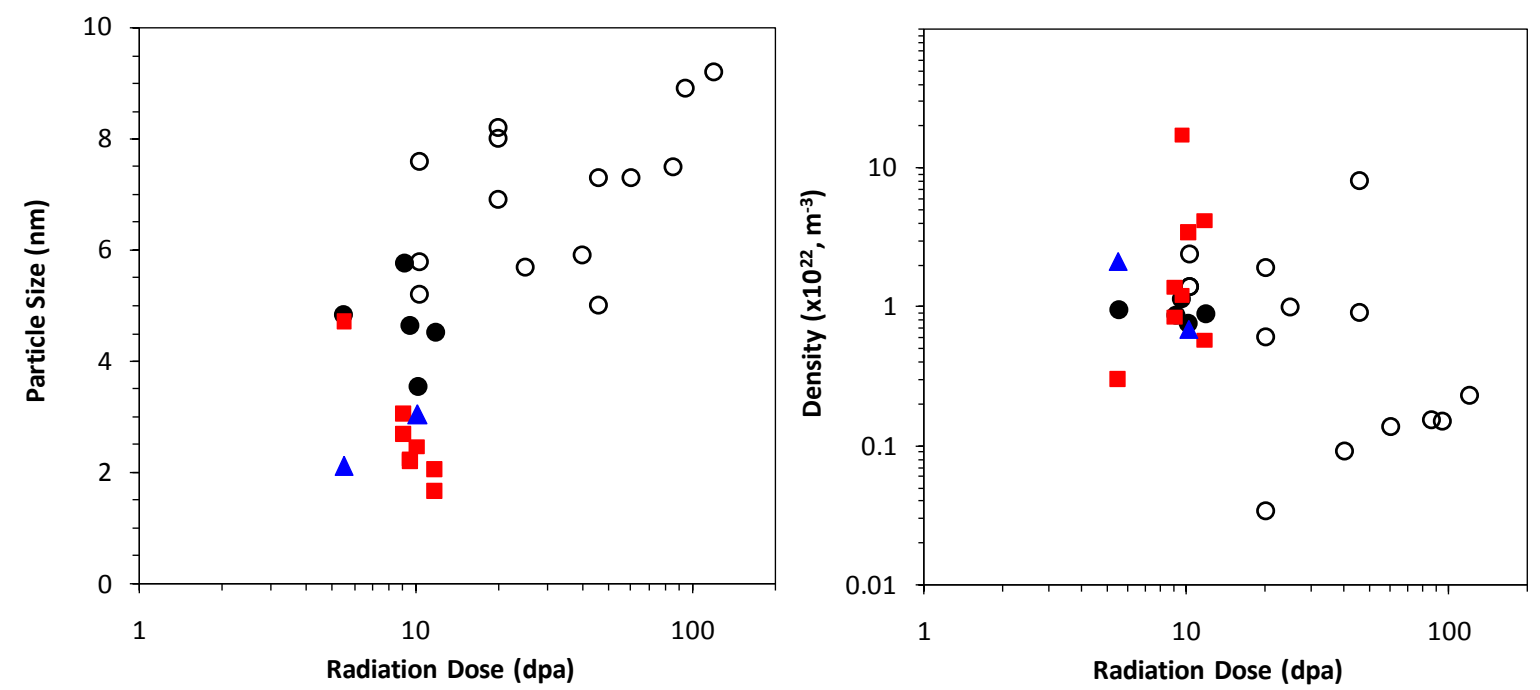

Figure 8. Radiation dose dependent size and density of the precipitates observed in this work (solid circles - G-phase, squares - unknown randomly orientated phase, triangles - $\gamma$ '-phase) as compared to literature data of G-phase (open circles). 


\subsubsection{Phase Transformation}

Three types of phase transformations were observed in the analyzed samples, mainly $\alpha$-ferrite in $\mathrm{AS} 18, \varepsilon$ '-martensite in SW37, and metastable CrC in LS13 as shown in Figure 9. The $\alpha$-ferrite observation was consistent with the large magnetic phase measurement result [10]. The formation of $\varepsilon$ '-martensite in SW37 was attributable to the lowest SFE of this alloy. The black phase, labeled with $\mathrm{P}$, was identified as $\mathrm{M}_{23} \mathrm{C}_{6}(\mathrm{M}=\mathrm{Cr}$-rich) by both diffraction pattern (inset) and EDS chemistry. Its adjacent small light gray section, labeled with $\mathrm{P} 1$, was measured to be $\mathrm{CrC}$ by EDS.
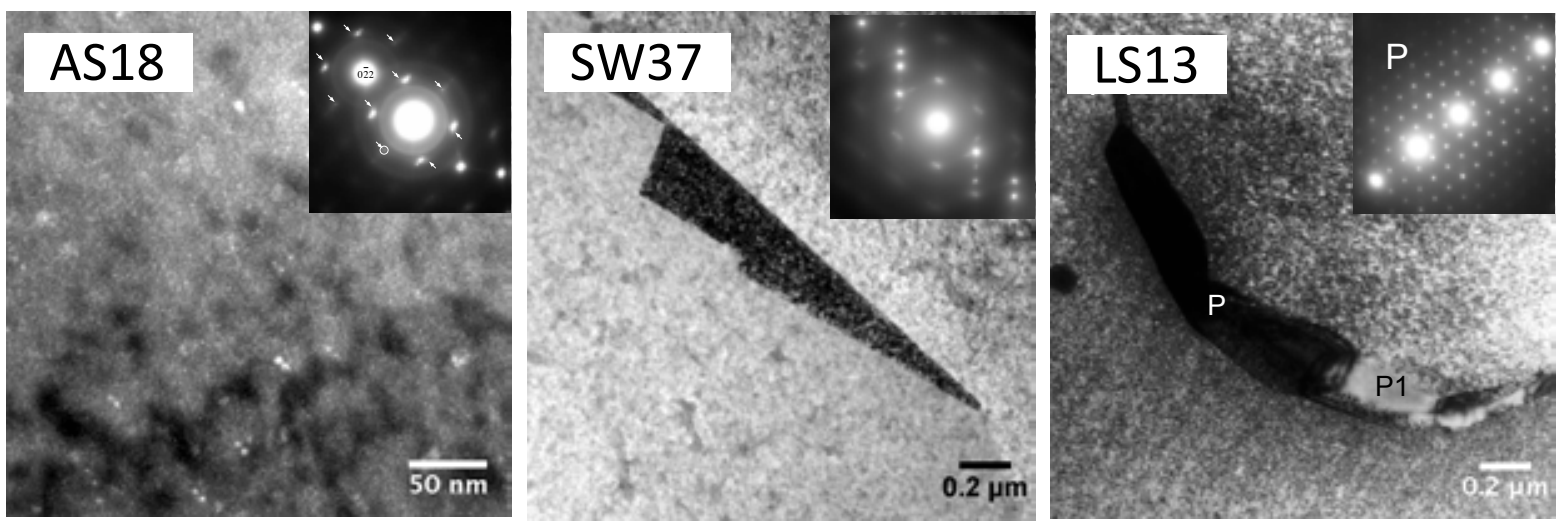

Figure 9. Three types of phase instabilities observed in the analyzed samples. 


\section{RADIATION INDUCED SEGREGATION (RIS) AT GRAIN BOUNDARIES}

Of primary interest for the RIS studies was the effect of major alloying elements on the RIS response, the effect of high irradiation dose ( $>25 \mathrm{dpa}$ ) on the RIS response, determining the sink characteristics of specific grain boundary types, and determining implications of grain boundary sink strength on near boundary precipitation. Several of the alloys of interest were utilized to determine these affects including K, L, A, and E. Alloy A was investigated at doses of $5.5 \mathrm{dpa}, 10.2 \mathrm{dpa}$, and $47.1 \mathrm{dpa}$ while all other alloys were investigated in the dose range of 9.1-11.8 dpa as listed in Table 1.

\subsection{INFLUENCE OF MAJOR ALLOYING ELEMENTS ON THE RIS RESPONSE}

The effect of bulk alloy composition was examined using the base alloys E (HP304), K (HP304+Ni) and $\mathrm{L}(\mathrm{HP} 304+\mathrm{Ni}+\mathrm{Cr}$ ) all irradiated at doses near steady state RIS conditions and the same irradiation temperature. In order to isolate the effects of bulk alloy composition only general high angle (HA) grain boundaries will be considered in this section. Figure 10 shows the change in the grain boundary concentration as a ratio of the $\mathrm{Cr} / \mathrm{Ni}$ bulk concentration for the alloys and conditions studied. As the $\mathrm{Cr} / \mathrm{Ni}$ ratio increases from .72 up to 1.52 the change in the Ni boundary concentration decreases while the change in the $\mathrm{Cr}$ boundary concentration shows a minimum near a $\mathrm{Cr} / \mathrm{Ni}$ ratio of 1.0. Similar results have been presented by Damcott et al. on proton irradiated $\mathrm{Fe}-\mathrm{Cr}-\mathrm{Ni}$ alloys where the change in the Ni boundary concentration decreased with increasing $\mathrm{Cr} / \mathrm{Ni}$ bulk concentration ratio and a saddle point was observed near a ratio of 1.17 [11]. An extensive work was completed by Allen et. al. investigating the effects of composition on RIS and indicated that RIS in Fe-Cr-Ni alloys is composition dependent due to changes in the diffusivities of $\mathrm{Fe}, \mathrm{Cr}$, and $\mathrm{Ni}$ with changes in the alloy composition [12]. The results presented here corroborate these findings.

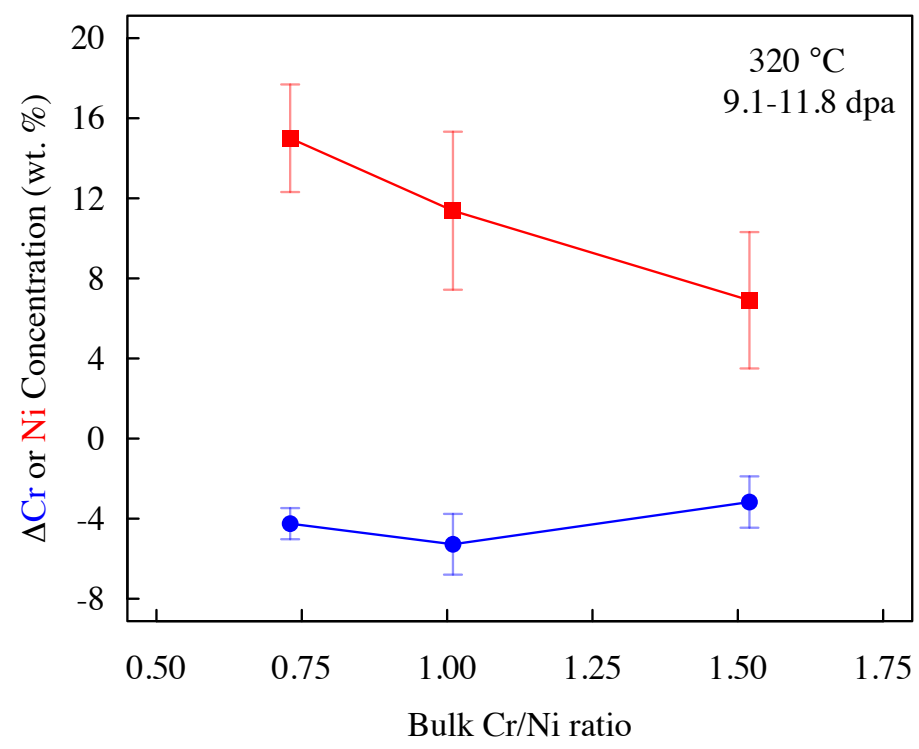

Figure 10. Measured change in $\mathrm{Cr}$ and $\mathrm{Ni}$ grain boundary concentrations as a function of bulk $\mathrm{Cr} / \mathrm{Ni}$ ratio at 9.8-11.8 dpa at $320^{\circ} \mathrm{C}$ for $\mathrm{HA}$ grain boundaries. 


\subsection{INTERPLAY BETWEEN GRAIN BOUNDARY STRUCTURE, IRRADIATION DOSE AND RIS}

Initial work in the late 1980's to the early 1990's simplified interpretation of RIS results by assuming all grain boundaries act as perfect sinks under irradiation. The perfect sink criterion implies the concentration of point defects (interstitials and vacancies) is maintained at thermal equilibrium. The advent of grain boundary engineering techniques for nuclear materials and a larger understanding of the local structure of grain boundaries and their interactions with point defects has sparked interest in understanding the local structure influence of grain boundaries on the RIS response. This work has been performed on both austenitic and ferritic/martensitic steels using both experiments and modeling across multiple institutions [13-24]. These studies have indicated different grain boundary types (i.e. low angle versus high angle) will have different sink characteristics (i.e. sink strength and efficiency) due variations in the density of point defect annihilation sites on the boundary, grain boundary energetics, and grain boundary diffusion. Given this, a majority of these studies have been conducted using accelerated ion beam irradiations or electron irradiations at fairly low dose ( $<10 \mathrm{dpa})$ and only on a limited alloy selection. In the perspective of the performance of austenitic stainless steels for long-term operation (LTO), it is favorable to verify the validity of the grain boundary structure theories to high doses ( $>25 \mathrm{dpa})$ and across multiple alloy compositions using neutron irradiation. Here, A-alloy was investigated up to 47.1 dpa to verify the dose dependencies on the grain boundary structure theory while low dose (9.1-11.8 dpa) samples of varying composition were investigated to determine the composition relationship with grain boundary structure theories.

Two-grain boundary types, general high angle (HA) grain boundaries and $\Sigma 3$ grain boundaries, dominated the type of grain boundary investigated for RIS. For $\Sigma 3$ grain boundaries, it is known the grain boundary plane can significantly impact the RIS response [13]. Here, no attempt was made to determine the grain boundary plane as the majority of $\Sigma 3$ grain boundaries showed identical RIS responses when the alloy composition and irradiation conditions were held constant. In general, neutron irradiated HA grain boundaries exhibited preferential enrichment of Ni to grain boundaries with corresponding depletion of $\mathrm{Fe}$ and $\mathrm{Cr}$ at all conditions and specimens investigated. On the other hand, $\Sigma 3$ grain boundaries suppressed or reduced the segregation response when compared to HA grain boundaries. For example, Figure 11 shows $1 \mathrm{D}$ segregation profiles for $\mathrm{Ni}$ and $\mathrm{Cr}$ for the twograin boundary types for the AS13 specimen. The 1D segregation profiles for the HA grain boundaries showed a sharp Ni enrichment peak with a full-width at half maximum of 3-5 nm, which is representative of the majority of HA grain boundaries investigated while the $\Sigma 3$ grain boundaries showed a nearly flat segregation profile.

Current theories indicates the RIS response observed for the alloys investigated here is due to the low point defect absorption and annihilation rates at low $\Sigma$-CSL grain boundaries due to the high boundary coherency and low grain boundary energetics while the HA grain boundaries typically exhibit a high point defect annihilation rate and low point defect retention due to the extensive secondary grain boundary dislocation network [18-21]. The differences in the point defect capture and annihilation processes at the different grain boundary types alters the point defect gradient seen at the different grain boundary types. Since RIS is directly correlated to the flux of point defects at defect sinks such as grain boundaries, so too is the RIS response. Although these theories are proving to be well established in literature, there remains an uncertainty in how grain boundary structure interrelates with irradiation dose, composition, and precipitation. Further work investigating these affects is discussed in the following. 
a)

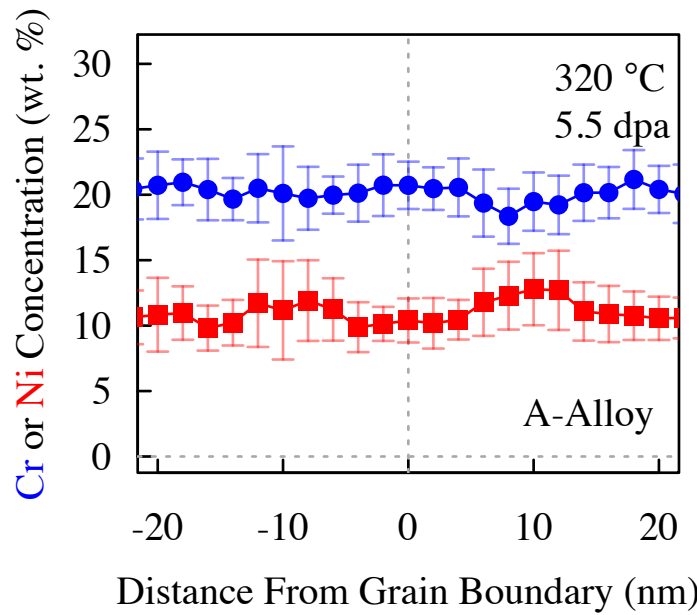

b)

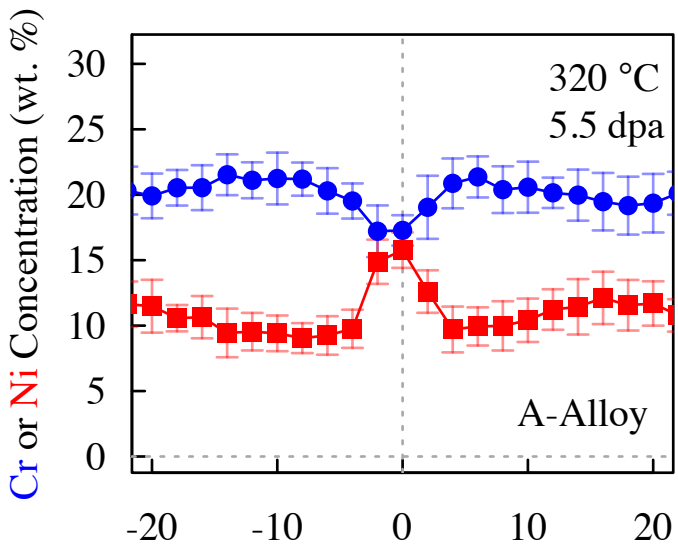

Distance From Grain Boundary (nm)

Figure 11. 1D concentration profiles from A-alloy irradiated 5.5 dpa at $320^{\circ} \mathrm{C}$. (a) Experimentally determined profile of a $\Sigma 3$ grain boundary. (b) Experimentally determined profile of a HA grain boundary.

The behavior of different grain boundary types as a function of dose is visualized in Figure 12 for alloy A (AS13, AS18, and AS23). The magnitude of the segregation response was monotonically increasing at HA grain boundaries with the most significant RIS response observed at $47.1 \mathrm{dpa}$. A sharp increase in the RIS response at doses below $\sim 5$ dpa occurs and nearly reaches steady state with $\sim 10$ wt. $\%$ Ni enrichment and $\sim 5 \mathrm{wt} . \% \mathrm{Cr}$ depletion on the HA grain boundaries above 30 dpa. This response for HA grain boundaries is consistent with the RIS versus dose trends commonly reported in literature for neutron irradiated austenitic steels [25]. $\Sigma 3$ grain boundaries did not display common dose trends in respect to RIS as a function of dose. The RIS response remained suppressed, with no significant segregation peaks, up to $47.1 \mathrm{dpa}$. The suppression of RIS, even to high dose, at $\Sigma 3$ grain boundaries suggests these grain boundary types are limited sinks for mobile point defects generated under neutron irradiation and their behavior remains independent of damage dose. The results on alloy A suggest specialized thermo-mechanical treatments (TMT) could be utilized to develop specialized grain boundary networks that reduce the percolation pathway for RIS susceptible grain boundaries by ensuring a high fraction of triple junctions which are comprised of two or more $\Sigma 3$ grain boundaries to doses relevant for LTO. 


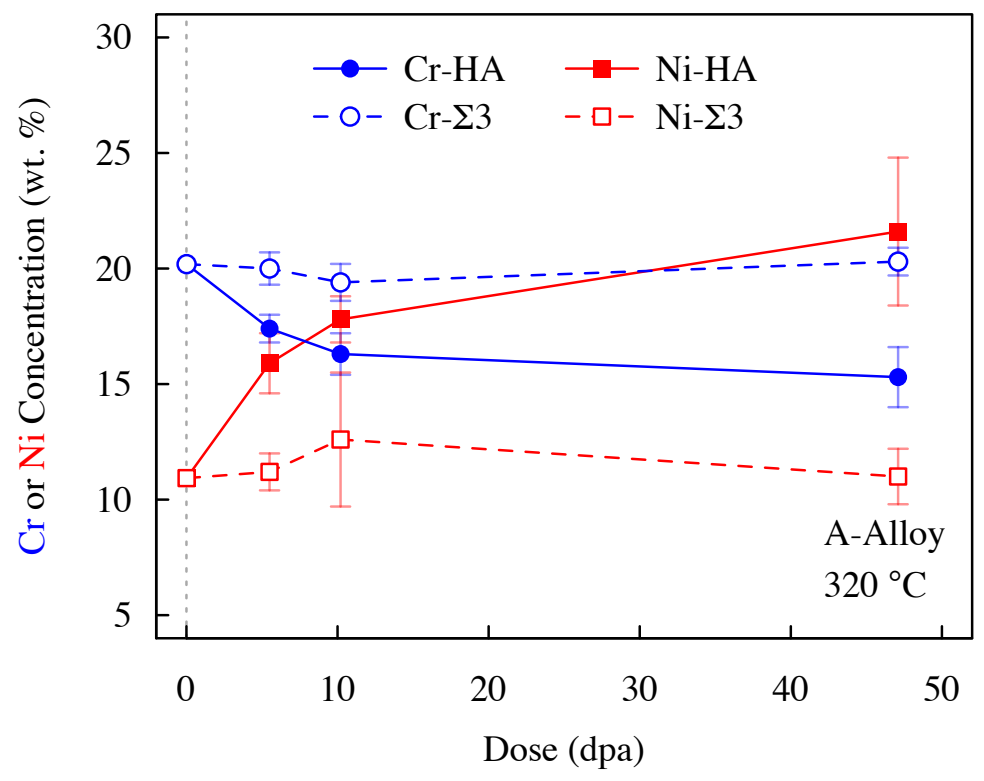

Figure 12. Average on-boundary concentrations of $\mathrm{Ni}$ and $\mathrm{Si}$ for different grain boundary types in Aalloy irradiated at varying doses at $320^{\circ} \mathrm{C}$.

The segregation response at HA and $\Sigma 3$ grain boundaries was also observed in KS13 and LS13 to similar doses to that of AS18 (9.6 dpa, $9.1 \mathrm{dpa}$, and $10.2 \mathrm{dpa}$ respectively). Figure 13 shows representative 1D segregation profiles of each alloy. The 1D segregation profiles shows the grain boundary structure response observed in alloy A is consistent with the RIS response observed in alloys $\mathrm{K}$ and $\mathrm{L}$ at $\mathrm{HA}$ and $\Sigma 3$ grain boundaries. Figure $13 \mathrm{~b}$ shows the segregation response of a $\Sigma 3$ grain boundary in alloy $\mathrm{K}$ which indicates a high RIS response as compared to other $\Sigma 3$ grain boundaries in other alloys. In alloy K, only one $\Sigma 3$ grain boundary was observed and therefore it can not be conclusively determined if the data shown in Figure 13b is an outlier although currently it is assumed the response observed is in relation to the grain boundary plane. Further work would be needed to verify this assumption.

Based on the presented results, it can be concluded that the point defect capture and annihilation processes occurring at grain boundaries is strongly dependent on the grain boundary internal structure but not on the starting alloy composition. As discussed, the composition does affect the diffusivities of $\mathrm{Fe}, \mathrm{Cr}$, and $\mathrm{Ni}$ and hence the reason $\mathrm{HA}$ grain boundaries exhibit different on boundary concentrations of $\mathrm{Cr}$ and $\mathrm{Ni}$ as a function of composition seen in Figure 13 but the suppression at $\Sigma 3$ grain boundaries observed in Figure 13 indicates that grain boundary structure also plays a dominate yet independent to composition role in the RIS response of Fe-Ni-Cr alloys. This is further supported by the open literature as suppression of RIS at $\Sigma 3$ grain boundaries has been observed across a wide variety of alloys including bec and fcc steels and irradiation conditions [13-24]. 
a)

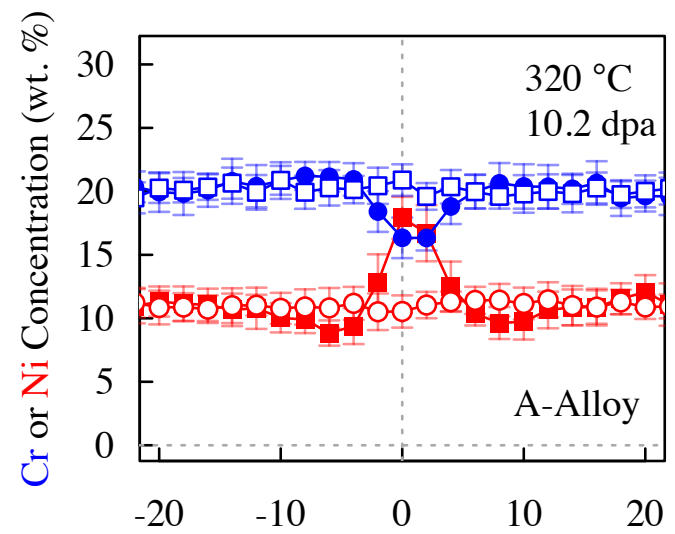

Distance From Grain Boundary (nm)

b)

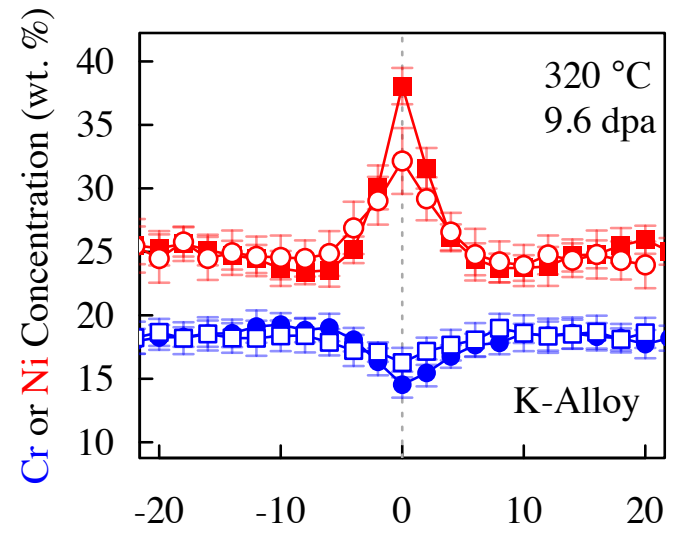

Distance From Grain Boundary (nm)

c) $\overparen{\partial}$

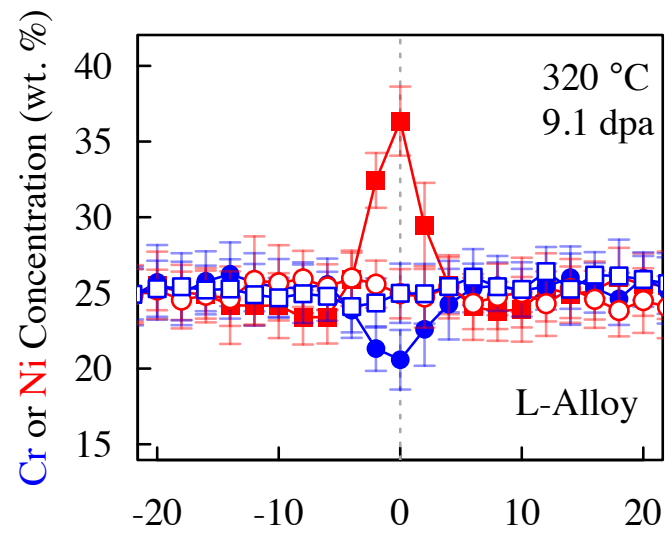

Distance From Grain Boundary (nm)

Figure 13. 1D concentration profiles showing the response of $\Sigma 3$ grain boundaries (open symbols) and HA grain boundaries (closed symbols) for alloys of varying composition. (a) A-alloy, (b) K-alloy, (c) Lalloy. 


\subsection{INFLUENCES OF RIS FOR ON BOUNDARY AND NEAR BOUNDARY PRECIPITATION}

Alloys investigated with sufficient Si content showed distinct Ni-Si rich clusters as a random distribution in the matrix. These clusters were also observed in spectrum images where Ni-Si clusters appeared to nucleate on $\Sigma 3$ grain boundaries but not in the vicinity or on HA grain boundaries as seen in Figure 14 for AS23 irradiated to $47.1 \mathrm{dpa}$. Figure 14 shows the integrated peak intensities at each pixel based on the spectrum image. The clusters are apparent in both the $\mathrm{Ni}-\mathrm{K}_{\alpha}$ and $\mathrm{Si}-\mathrm{K}_{\alpha}$ maps, indicating that the clusters are rich in $\mathrm{Ni}$ and $\mathrm{Si}$ although the exact composition cannot be determined due to significant matrix contributions during analysis. Similar issues with matrix contributions are common in STEM-EDS maps of small precipitates in irradiated TEM specimens [26]. Given this, previous works on austenitic alloys with sufficient Si content have indicated the clusters are either $\gamma$ ' $\left(\mathrm{Ni}_{3} \mathrm{Si}\right)$ or G-phase $\left(\mathrm{M}_{6} \mathrm{Ni}_{16} \mathrm{Si}_{7}\right)$ [27-29]. Recent thermodynamic modeling by Yang et al. has shown that G-phase likely as it is a thermodynamically stable phase and has the potential to form under irradiation [30] but significantly more characterization is needed to conclusively determine the exact phase of the Ni-Si clusters.

It is interesting to note the Ni-Si clusters formed on $\Sigma 3$ grain boundaries but similar morphologies were not seen at HA grain boundaries. It is probable that the formation of these Ni-Si clusters are associated with preferential nucleation sites such as dislocations which comprise a $\Sigma 3$ grain boundary which contains small deviations from the exact CSL orientation. Further work is needed to understand the underlying mechanisms and any relationship between the formation of Ni-Si clusters, RIS, and defect sink characteristics.

a)

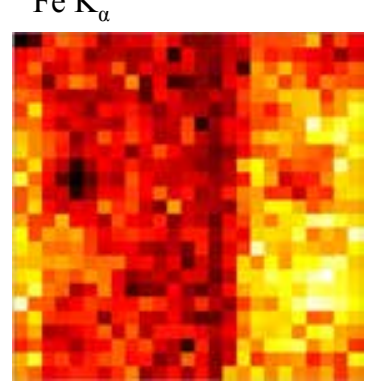

$\mathrm{Cr} \mathrm{K}_{\alpha}$

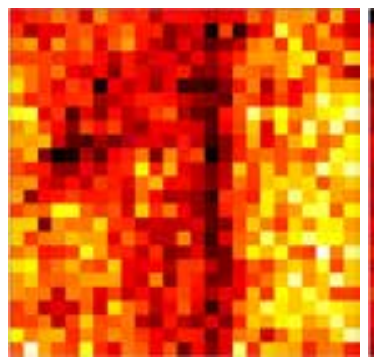

$\mathrm{Ni} \mathrm{K}$

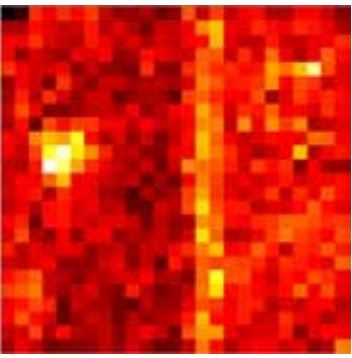

$\mathrm{Ni} \mathrm{K}$

b) $\quad \mathrm{Fe} \mathrm{K}$

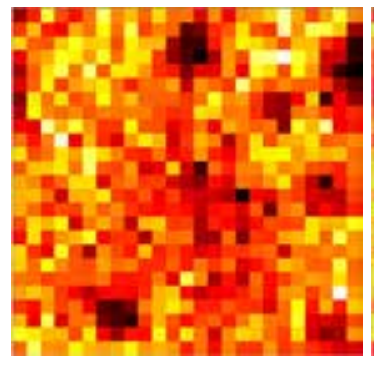

$\mathrm{Cr} \mathrm{K}_{\alpha}$

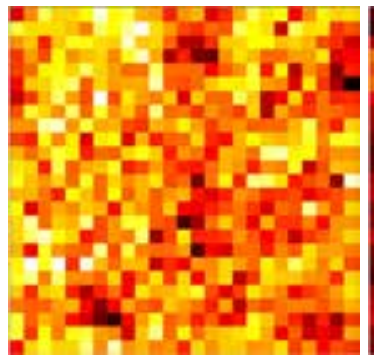

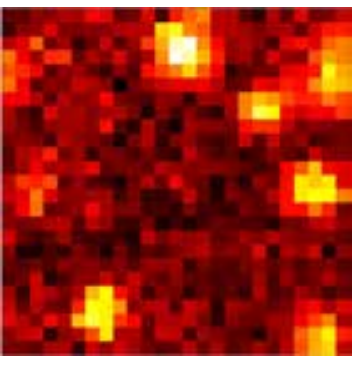

Si K $\alpha$

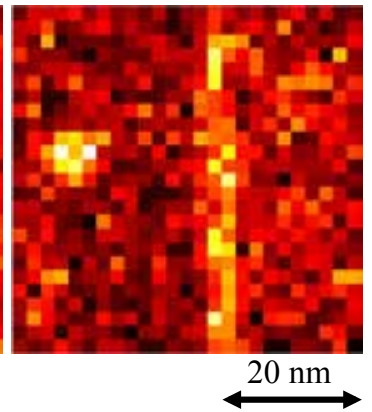

Si K $\mathrm{K}_{\alpha}$

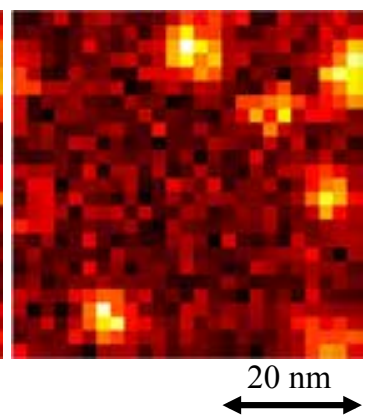

Figure 14. Elemental EDS maps extracted from spectrum images showing the Ni-Si cluster formations near grain boundaries in A-alloy irradiated to $47.1 \mathrm{dpa}$. Grain boundaries run top to bottom of the page. (a) HA grain boundary, (b) $\Sigma 3$ grain boundary. 


\section{RADIATION INDUCED HARDENING}

Radiation induced microstructure evolution usually results in yield strength increase that is typically expressed in the form of

$$
\Delta \sigma_{Y S}=\sqrt{\sum_{i} \Delta \sigma_{p_{i}}^{2}+\Delta \sigma_{c}^{2}+\Delta \sigma_{L}^{2}}+\Delta \sigma_{D}
$$

denoting the superposition rule of the strength contributions $(\Delta \sigma)$ from the $i$-th type of precipitate $\left(\mathrm{p}_{i}\right)$, cavities (c), Frank loops (L), and dislocation network (D). Dislocation network was not observed in the irradiated samples and thus is not considered here. It is assumed that RIS does not have a significant effect on hardening.

\subsection{PRECIPITATES}

Two mechanisms are considered for precipitate strengthening during dislocation-precipitate interaction. One is classic Orowan mechanism that dislocation bows around the precipitate, which is expected to occur on large coherent, semi-coherent, or incoherent precipitates. The other is dislocation shearing the precipitate that is usually small and coherent.

The accepted version of the Orowan equation for spherical particles is given by [31]:

$$
\Delta \tau_{O s}=\frac{B}{L_{s}-\bar{d}} \ln \left(\frac{\bar{d}}{r_{o}}\right)
$$

with the parameter $B=\frac{0.85 \mu b}{2 \pi(1-v)^{1 / 2}}$ for isotropic material as a function of shear modulus $(\mu)$,

magnitude of Burgers vector $(b)$, and Poisson's ratio $(v)$, particle interspacing $L_{s}=\sqrt{\frac{\pi d^{2}}{6 f}}$ with volume fraction $(f)$ as a function of average particle diameter $(d)$ and volumetric number density $\left(N, \mathrm{~m}^{-3}\right)$ as $f=\frac{\pi}{6} d^{3} N$, the geometry-corrected effective sphere diameter $\bar{d}=\sqrt{\frac{2}{3}} d[32]$ in the slip plane, and the dislocation core radius $r_{o}=b$ at room temperature. Accordingly, the yield strength induced by spherical particles can be deduced by including Taylor factor $(\mathrm{M}=3.06$ for fcc polycrystals $)$ and the Possion's ratio $(v=0.29)$ for AISI 304 stainless steel at room temperature as:

$$
\Delta \sigma_{O s}=\frac{0.491 \mu b \sqrt{N d}}{1-0.816 d \sqrt{N d}} \ln \left(\frac{0.816 d}{b}\right)
$$

In the case of aligned thin plate shaped particles with diameter $D$ and thickness $t$, the Orowan equation is given as:

$$
\Delta \sigma_{o p}=\frac{M B}{\lambda} \ln \left(\frac{\bar{D}}{r_{o}}\right)
$$

where the effective interparticle spacing $\lambda=\frac{L}{1+P / L}-\bar{t}$ with $L=\sqrt{\frac{D t}{f}}, f=\frac{\pi}{4} D^{2} t N, P=\bar{D}-\bar{t}$, $\bar{D}=\frac{2 D}{\pi}$, and $\bar{t}=\frac{\pi t}{2}[32]$. Thus, the yield strength induced by aligned thin plate shaped particles in AISI 304 at room temperature is given by: 


$$
\Delta \sigma_{O p}=\frac{0.0614 \mu b A}{1-0.196 t A} \ln \left(\frac{0.637 D}{b}\right)
$$

with $A=\sqrt{16 \pi N D}+4 N D^{2}-\pi^{2} N D t$.

The yield strength increase by shearing small coherent precipitates $\left(\Delta \sigma_{S}\right)$ originates from the contributions of order strengthening $\left(\Delta \sigma_{1}\right)$, coherency strengthening $\left(\Delta \sigma_{2}\right)$, modulus mismatch strengthening $\left(\Delta \sigma_{3}\right)$, stacking-fault strengthening, and chemical strengthening in a descending order of contribution magnitude [33]. The first contribution is given by [34]:

$$
\Delta \sigma_{1}=\frac{M \gamma_{p} \bar{d}}{b(L-\bar{d})}
$$

where $\gamma_{\mathrm{p}}\left(\mathrm{J} / \mathrm{m}^{2}\right)$ is the surface energy due to disordering the specific coherent precipitate. It can be estimated by:

$$
\gamma_{p}=\frac{8 S^{2} R T_{c}}{2.18 \times 3 \sqrt{3} a^{2} N_{A}}=9.75 \times 10^{-24} S^{2} T_{c} / a^{2}
$$

for $\mathrm{AB}_{3}$ type simple cubic precipitates in fcc matrix by adapting from [35], where $\mathrm{S}$ is the long-range order parameter, $\mathrm{R}$ the gas constant, $\mathrm{T}_{\mathrm{c}}$ the critical ordering temperature for dissolution of the precipitates, $a$ the lattice parameter of the matrix, and $\mathrm{N}_{\mathrm{A}}$ Avogadro constant. According to the parameters defined above, the order strengthening contribution to yield strength by shearing small sphere coherent precipitates can be derived as:

$$
\Delta \sigma_{1 s}=\frac{2.50 \gamma_{p} d \sqrt{N d}}{b(1-0.816 d \sqrt{N d})}
$$

The second contribution is adapted from [33] as:

$$
\Delta \sigma_{2}=M \chi \mu \varepsilon^{3 / 2} \sqrt{\frac{\bar{d} f}{b}}
$$

where $\chi$ is a constant differing from one theory to the other, varying between 2 and 3 , and $\varepsilon \approx$ $(2 / 3)(\Delta \mathrm{a} / \mathrm{a})$ is the constrained lattice parameter mismatch between precipitate and matrix. With $\chi=$ 2.6, Equation ( 12 ) for sphere coherent precipitates is simplified as:

$$
\Delta \sigma_{2 s}=5.20 \mu \varepsilon^{3 / 2} d^{2} \sqrt{\frac{N}{b}}
$$

The third contribution is adapted from [33] as:

$$
\Delta \sigma_{3}=0.0055 M(\Delta \mu)^{3 / 2} \sqrt{\frac{2 f}{\mu}}\left(\frac{\bar{d}}{2 b}\right)^{\frac{3 m}{2}-1}
$$

with $m$ as a constant $(=0.85)$ and $\Delta \mu$ the shear modulus mismatch between the matrix and the precipitates. For sphere coherent precipitates, Equation ( 14 ) is simplified as: 


$$
\Delta \sigma_{3 s}=0.0135(\Delta \mu)^{3 / 2} \sqrt{\frac{d^{3} N}{\mu}}\left(\frac{d}{b}\right)^{0.275}
$$

\subsection{FRANK LOOPS}

Frank loops are generated by vacancies or interstitials coalescing as platelets between two adjacent $\{111\}$ close-packed planes, which can be considered as aligned plate-shaped obstacles with measured diameter $(D)$ and thickness $(t)$ as the Burgers vector of $\{111\}$ planes. Thus, their strengthening contribution can be estimated by equation ( 8 ).

\subsection{CAVITIES}

The cavity hardening equation developed by Scattergood and Bacon [36] is given by:

$$
\Delta \sigma_{c}=\frac{k_{1} \mu b \sqrt{N d}}{1-0.816 d \sqrt{N d}} \ln \left[\frac{0.816 d}{k_{2} b}(1-0.816 d \sqrt{N d})\right]
$$

with the fitting parameters $\mathrm{k}_{1}=1.39$ and $\mathrm{k}_{2}=3.3$. It has been suggested that cavity hardening may have contribution when their sizes are larger than $1 \mathrm{~nm}$ and the contribution becomes significant as their size larger than about $4 \mathrm{~nm}$ [34]. Smaller cavities not only cannot significantly lower the dislocation energy, but also can be bypassed by cross slip or climb during slow deformation processes.

\subsection{RADIATION HARDENING}

The dispersed barrier hardening model is often used to estimate radiation hardening, which is simplified in the form of [37]

$$
\Delta \sigma_{y}=M \alpha \mu b \sqrt{N d}
$$

by introducing a parameter of strength factor $\alpha$. Lucas [37] reviewed the $\alpha$ in austenitic stainless steels for Frank loops, cavities and precipitates in the range of 0.2 to $\sim 1$. Comparing this equation to the equations for the three types of defects developed above, we can see that strength factor is approximately in the form of $\alpha=\mathrm{k}_{1} \times \ln \left(\mathrm{k}_{2} \times d\right)$ with $\mathrm{k}_{1}$ and $\mathrm{k}_{2}$ as fitting parameters, which is strongly dependent upon defect size $(d)$.

For the analyzed samples of the BOR-60 irradiated type AISI 304 and 316 variants, the radiation hardening is primarily attributed to the Frank loops (Table 2), precipitates (Table 4), and cavities (Table 3). With fcc matrix lattice parameter $\mathrm{a}=0.358 \mathrm{~nm}, \mathrm{~b}=\sim 0.253 \mathrm{~nm}, \mu=\sim 86 \mathrm{GPa}$ (AISI 304) and $\mu=$ $\sim 77 \mathrm{GPa}$ (AISI 316L) at room temperature, the strength factors of Frank loops, spherical Orowan precipitates, and cavities were calculated according to the above equations and are plotted in Figure 15. The literature data of the respective type of defects in similar alloys irradiated in the same or similar conditions are also included as open symbols. In general, the overall data are consistent, which are well fitted with an equation of $\alpha=\mathrm{k}_{1} \times \ln \left(\mathrm{k}_{2} \times d\right)$, considering the uncertainties from the alloy chemistry effect on Poisson's ratio and the characterization capabilities of different TEM facilities. The data of Frank loops show the largest deviation from their fitting result. One of the examples is the largest size of Frank loop $(25.5 \mathrm{~nm})$ measured in a 304 variant with reduced amount 
of sulfur [7]. Due to the limited available data, the data of cavities show the least deviation. The strength factor of $\gamma^{\prime}$-phase is not shown in Figure 15 since this phase follows a dislocation shearing mechanism, leading to a calculation equation different from the one used in Figure 15 only for spherical precipitates following the Orowan mechanism.
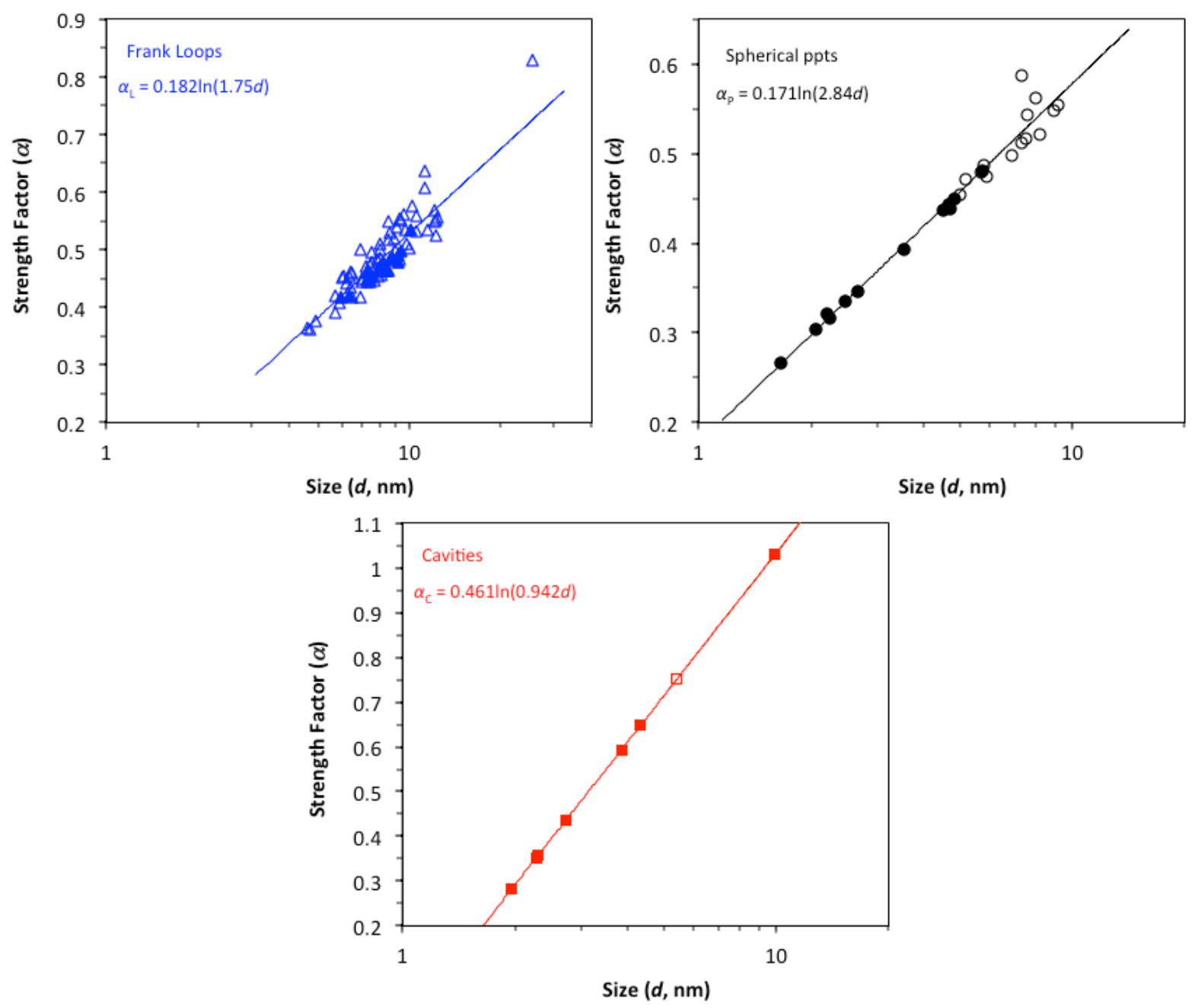

Figure 15. Strength factor $\alpha$ of Frank loops, spherical Orowan precipitates, and cavities (solid symbols this work, open symbols - literature data).

With the formulated strength factors for the three types of defects, radiation hardening can be easily calculated using the equations (17) and (4). The effect of phase instability presented in Section 3.3.3 on hardening is not considered here. Figure 16 plots the calculated hardening as compared to the measured hardening [1] of the analyzed samples. The errors of the calculated hardening are primarily attributable to Frank loops due to their large deviations as shown in Table 2. The measured results were retrieved from ball indentation experimental data due to the limited size of irradiated samples. In general, the calculated results are in good agreement with the measured ones, considering the uncertainties from the effect of alloy chemistry and cold work on shear modulus and Poisson's ratio, characterization uncertainty of the TEM, and the uncertainty during retrieving the limited ball indentation data. 


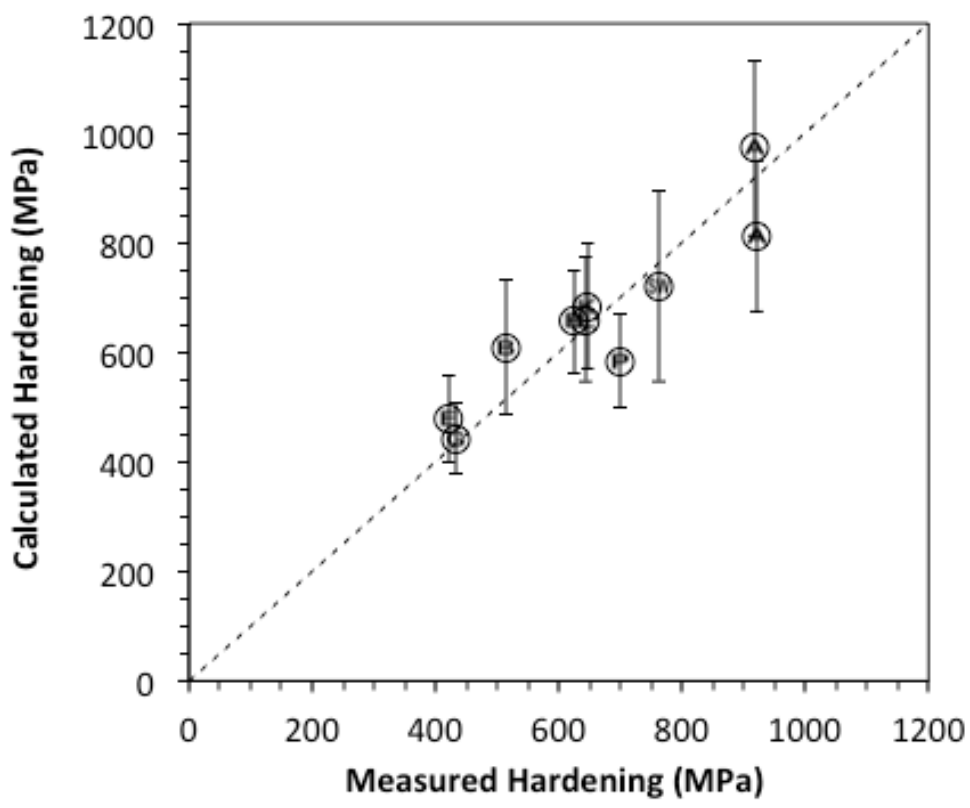

Figure 16. Agreement between calculated and measured radiation hardening of the analyzed samples. 


\section{CONCLUSIONS}

A set of well designed type 304 and 316 variants by changing the amount of a single solute element were irradiated using the BOR-60 fast breeder reactor at $\sim 320^{\circ} \mathrm{C}$ in Russia. This set of alloy samples has been used in this work to characterize detailed microstructural evolution induced by the neutron irradiation. Conventional and scanning transmission electron microscopy (CTEM/STEM) and energy dispersive X-ray spectroscopy (EDS) were primarily employed.

A total of eleven irradiated samples from nine alloys have been characterized. Frank loops and ultrafine precipitates are major features observed in these samples. Additionally, a few ultrafine cavities were observed in most of analyzed samples, which have not been reported in the studies on similar alloys irradiated at the same or similar conditions. It was found that the size of Frank loops slightly increases with higher equivalent $\mathrm{Cr}$ content and the density decreases with higher stacking fault energy of the alloys. The irradiation did not alter the pre-existing $\mathrm{M}_{23} \mathrm{C}_{6}(\mathrm{M}=\mathrm{Cr}$-rich) and Laves phases, but introduced nano-scale $\mathrm{M}_{23} \mathrm{C}_{6}$ and noticeable amounts of ultrafine G-phase, $\gamma$ 'phase, and unknown phases in $\mathrm{L}_{2}$ and $\alpha^{\prime}$ (Cr-rich) structures in different samples. Phase transformations with the formation of $\alpha$-ferrite, $\varepsilon$ '-martensite, and possible $\mathrm{CrC}$ phases were observed in three of the samples. Higher radiation dose tends to increase the size but decrease the density of Frank loops and precipitates in different levels. Due to the limited amount of cavities observed in the samples, their relationship with alloy chemistry and radiation dose was not able to be determined.

A subset of specimens was investigated for RIS. It was found the segregation response is dependent on the bulk alloy composition. Increasing the $\mathrm{Cr} / \mathrm{Ni}$ ratio of the bulk concentration decreased the change in $\mathrm{Ni}$ concentration at the boundary but the change in $\mathrm{Cr}$ concentration dependency was more complex with a minimum change seen near $\mathrm{Cr} / \mathrm{Ni}$ ratios around 1.0. Grain boundary structure (or type of grain boundary) was found to also strongly influence the RIS response across all alloys and doses investigated with $\Sigma 3$ grain boundaries completely suppressing the RIS response. The structure dependence was found to be independent of bulk composition or damage dose. Initial work indicates the compounding factors of damage dose, grain boundary structure, and local composition could also impact the formation of Ni-Si clusters in the vicinity of grain boundaries in alloys with sufficient $\mathrm{Si}$ contents.

The general accepted dispersed barrier hardening model was used to estimate radiation hardening. However, the strength factor $(\alpha)$ in the hardening model is not well defined, which is usually obtained by approximation from references or back-calculation from measured strength of irradiated samples. To be able to directly estimate radiation hardening, a model of strength factor was developed in this work in the form of $\alpha=\mathrm{k}_{1} \times \ln \left(\mathrm{k}_{2} \times d\right)$ with $d$ for the size of Frank loops, precipitates and cavities, and $\mathrm{k}_{1}$ and $\mathrm{k}_{2}$ as fitting parameters. The calculated radiation hardening results using the strength factor model and the dispersed barrier hardening model are in good agreement with experimental results.

The results of this work provide invaluable insights into understanding degradation mechanisms of key components and assists in the prediction of the life of similar materials and the base knowledge required to develop advanced radiation resistant alloys. 


\section{REFERENCES}

1. M. Gussev, L. Tan, J.T. Busby, Analysis of irradiation-induced phase transformations under LWR relevant conditions, ORNL/LTR-2012/436.

2. J.-J. Fundenberger, A. Morawiec, E. Bouzy, J.S. Lecomte, Polycrystal orientation maps from TEM, Ultramicroscopy, 96 (2003) 127 - 137.

3. D.G. Brandon, The structure of high-angle grain boundaries, Acta Metallurgica, 14 (1966) 1479 1484.

4. D.J. Edwards, A. Schemer-Kohrn, S. Bruemmer, Characterization of neutron-irradiated 300series stainless steels, EPRI, Palo Alto, CA: 2006. 1009896.

5. D.J. Edwards, S.M. Bruemmer, Characterization of CIR II irradiated stainless steels, EPRI, Palo Alto, CA, EP-P19021/C9406, 2008.

6. Y. Yang, Y. Chen, Y. Huang, T. Allen, A. Rao, Irradiation microstructure of austenitic steels and cast steels irradiated in the BOR-60 reactor at $320^{\circ} \mathrm{C}$, in: J.T. Busby, G. Ilevbare, P.L. Andresen (Eds.), $15^{\text {th }}$ International Conference on Environmental Degradation, TMS (The Minerals, Metals \& Materials Society), 2011.

7. Y. Chen, O.K. Chopra, W.K. Soppet, W.J. Shack, Y. Yang, T. Allen, A.S. Rao, Cracking behavior and microstructure of austenitic stainless steels and alloy 690 irradiated in BOR-60 reactor, phase I, Argonne National Laboratory, ANL/09-32.

8. Y. Yang, T.R. Allen, Y. Chen, O.K. Chopra, Dose dependence of radiation hardening of austenitic steels in Bor-60 at PWR-relevant temperatures, 14th Int. Conf. Environ. Degrad. Mater. Nucl. Power Syst., Virginia Beach, VA, US, August 23-27, 2009.

9. A.-É. Renault, C. Pokor, J. Garnier, J. Malaplate, Microstructure and grain boundary chemistry evolution in austenitic stainless steels irradiated in the BOR-60 reactor up to $120 \mathrm{dpa}, 14^{\text {th }} \mathrm{Int}$. Conf. on Environmental Degradation of Materials in Nuclear Power Systems, Virginia Beach, VA, August 23-27, 2009.

10. M.N. Gussev, J.T. Busby, L. Tan, F.A. Garner, Magnetic phase formation in irradiated austenitic alloys, J. Nucl. Mater. 448 (2014) 294-300.

11. D.L. Damcott, T.R. Allen, G.S. Was, Dependence of radiation-induced segregation on dose, temperature and alloy composition in austenitic alloys, J. Nucl. Mater., 225 (1995) 97-107.

12. T.R. Allen, G.S. Was, E.A. Kenik, The effect of alloy composition on radiation-induced segregation in Fe-Cr-Ni alloys, J. Nucl. Mater., 244 (1997) 278-294.

13. C.M. Barr, G.A. Vetterick, K.A. Unocic, K. Hattar, X.-M. Bai, M.L. Taheri, Anisotropic radiation-induced segregation in $316 \mathrm{~L}$ austenitic stainless steel with grain boundary character, Acta Materialia, 67 (2014) 145-155.

14. M. Tomozawa, Y. Miyahara, K. Kako, Solute segregation on $\Sigma 3$ and random grain boundaries in type 316L stainless steel, Materials Science and Engineering: A, 578 (2013) 167-173.

15. R. Hu, G.D.W. Smith, E.A. Marquis, Effect of grain boundary orientation on radiation-induced segregation in a Fe-15.2at.\% Cr alloy, Acta Materialia, (2013).

16. E.A. Marquis, S. Lozano-Perez, V. de Castro, Effects of heavy-ion irradiation on the grain boundary chemistry of an oxide-dispersion strengthened Fe-12 wt.\% Cr alloy, Journal of Nuclear Materials, 417 (2011) 257-261. 
17. N. Sakaguchi, S. Watanabe, H. Takahashi, R.G. Faulkner, A multi-scale approach to radiationinduced segregation at various grain boundaries, Journal of Nuclear Materials, 329-333 (2004) 1166 - 1169.

18. T.S. Duh, J.J. Kai, F.R. Chen, Effects of grain boundary misorientation on solute segregation in thermally sensitized and proton-irradiated 304 stainless steel, Journal of Nuclear Materials, 283287 (2000) $198-204$.

19. T.S. Duh, J.J. Kai, F.R. Chen, L.H. Wang, Numerical simulation modeling on the effects of grain boundary misorientation on radiation-induced solute segregation in 304 austenitic stainless steels, Journal of Nuclear Materials, 294 (2001) 267 - 273.

20. K.G. Field, L.M. Barnard, C.M. Parish, J.T. Busby, D. Morgan, T.R. Allen, Dependence on grain boundary structure of radiation induced segregation in a $9 \mathrm{wt} . \% \mathrm{Cr}$ model ferritic/martensitic steel, Journal of Nuclear Materials, 435 (2013) 172-180.

21. K.G. Field, B.D. Miller, H.J.M. Chichester, K. Sridharan, T.R. Allen, Relationship between lath boundary structure and radiation induced segregation in a neutron irradiated $9 \mathrm{wt} . \% \mathrm{Cr}$ model ferritic/martensitic steel, Journal of Nuclear Materials, 445 (2014) 143-148.

22. S. Watanabe, Y. Takamatsu, N. Sakaguchi, H. Takahashi, Sink effect of grain boundary on radiation-induced segregation in austenitic stainless steel, Journal of Nuclear Materials, 283-287 (2000) 152-156.

23. N. Sakaguchi, M. Endo, S. Watanabe, H. Kinoshita, S. Yamashita, H. Kokawa, Radiationinduced segregation and corrosion behavior on $\Sigma 3$ coincidence site lattice and random grain boundaries in proton-irradiated type-316L austenitic stainless steel, Journal of Nuclear Materials, 434 (2013) 65-71.

24. G.-G. Lee, H.-H. Jin, Y.-B. Lee, J. Kwon, Observation and rate theory modeling of grain boundary segregation in $\Sigma 3$ twin boundaries in ion-irradiated stainless steel 316, Journal of Nuclear Materials, 449 (2014) 234-241.

25. K. Fukuya, Current understanding of radiation-induced degradation in light water reactor structural materials, Journal of Nuclear Science and Technology, 50 (2013) 213-254.

26. A.G. Certain, K.G. Field, T.R. Allen, M.K. Miller, J. Bentley, J.T. Busby, Response of nanoclusters in a $9 \mathrm{Cr}$ ODS steel to $1 \mathrm{dpa}, 525{ }^{\circ} \mathrm{C}$ proton irradiation, Journal of Nuclear Materials, 407 (2010) 2-9.

27. Z. Jiao, G.S. Was, Novel features of radiation-induced segregation and radiation-induced precipitation in austenitic stainless steels, Acta Materialia, 59 (2011) 1220-1238.

28. K.C. Russell, Phase Stability Under Irradiation, Progress in Materials Science, 28 (1984) 229434.

29. L. E.H., P.J. Maziasz, A.F. Rowcliffe, Phase stability during irradiation : proceedings of a symposium sponsored by the Nuclear Metallurgy Committee at the Fall Meeting of The Metallurgical Society of AIME, in: J.R. Holland, L.K. Mansur, D.J. Potter (Eds.) Phase Stability During Irradiation, The Metallurgical Society of AIME, Pittsburgh, Pennsylvania, 1980, pp. 191218.

30. Y. Yang, J.T. Busby, Thermodynamic modeling and kinetics simulation of precipitate phases in AISI 316 stainless steels, Journal of Nuclear Materials, 448 (2014) 282-293.

31. P.B. Hirsch, F.J. Humphreys, Plastic deformation of two-phase alloys containing small nondeformable particles, in: A.S. Argon (Ed.), Physics of Strength and Plasticity, M. I. T. Press, 1969 , p.189. 
32. P.M. Kelly, The effect of particle shape on dispersion hardening, Scripta Metall. 6 (1972) 647 656.

33. A.J. Ardell, Precipitation hardening, Met. Trans. A 16 (1985) 2131-2165.

34. R.L. Simons, L.A. Hulbert, Correlation of yield strength with irradiation-induced microstructure in AISI type 316 stainless steel, in: F.A. Garner, J.S. Perrin (Eds.), Effects of Radiation on Materials: Twelfth International Symposium, ASTM STP 870, American Society for Testing and Materials, Philadelphia, 1985, pp. 820-839.

35. R.O. Williams, Origin of strengthening on precipitation: ordered particles, Acta Metall. 5 (1957) 241-244.

36. R.O. Scattergood, D.J. Bacon, The strengthening effect of voids, Acta Metall. 30 (1982) 1665 1677.

37. G.E. Lucas, The evolution of mechanical property change in irradiated austenitic stainless steels, J. Nucl. Mater. 206 (1993) 287-305. 
This page intentionally left blank 
ORNL/TM-2014/303

\section{INTERNAL DISTRIBUTION}

\begin{tabular}{ll}
\hline Name & Email Address \\
\hline Busby, J.T. & busbyjt@ornl.gov \\
Field, K.G. & fieldkg@ornl.gov \\
Gussev, M.N. & gussevmn@ornl.gov \\
Rosseel, T.M. & rosseeltm@ornl.gov \\
Tan, L. & tanl@ornl.gov \\
Williams, D.L. & williamsdljr@ornl.gov \\
Yang, Y. & yangying@ornl.gov \\
\hline
\end{tabular}

\section{EXTERNAL DISTRIBUTION}

R. Reister, GTN Bldg, 1000 Independence Ave, S.W. Washington, DC 20585, (Richard.Reister@nuclear.energy.gov) 
